\title{
WHO BECOMES A POLITICIAN?*
}

\author{
Ernesto Dal Bó, Frederico Finan, Olle Folke, \\ Torsten Persson, and Johanna Rickne
}

March 2017

Can a democracy attract competent leaders, while attaining broad representation? Economic models suggest that free-riding incentives and lower opportunity costs give the less competent a comparative advantage at entering political life. Moreover, if elites have more human capital, selecting on competence may lead to uneven representation. This paper examines patterns of political selection among the universe of municipal politicians and national legislators in Sweden, using extraordinarily rich data on competence traits and social background for the entire population. We document four new facts that together characterize an "inclusive meritocracy." First, politicians are on average significantly smarter and better leaders than the population they represent. Second, this positive selection is present even when conditioning on family (and hence social) background, suggesting that individual competence is key for selection. Third, the representation of social background, whether measured by parental earnings or occupational social class, is remarkably even. Fourth, there is at best a weak tradeoff in selection between competence and social representation, mainly due to strong positive selection of politicians of low (parental) socioeconomic status. A broad implication of these facts is that it is possible for democracy to generate competent and socially-representative leadership.

${ }^{*}$ We thank the editors Andrei Shleifer and Larry Katz, three anonymous referees, as well as participants in numerous seminars and conferences for their helpful comments. We thank Josh Halberstam, Richard Öhberg, Daniele Paserman, Mikael Persson, Martín Rossi and Juan Vargas for their discussions of the paper, and gratefully acknowledge financial support from the Torsten Söderberg Foundation and the Swedish Research Council. Jonas Allerup, Johan Arntyr, Sirus Dehdari, Johannes Hermle, Roza Khoban, and Elin Molin provided excellent research assistance. 


\section{INTRODUCTION}

The identity of politicians influence which policies get selected, how well they are implemented, and who benefits from them. ${ }^{1}$ This is undisputable for autocracies where rulers face few constraints. But it is also true for representative democracies, as policy platforms do not constitute complete enforceable contracts. Most voters would therefore like to elect highly able policymakers for choosing and implementing policies to attain a given objective (throughout, we use "able" and "competent" interchangeably). As a collective, voters may also want to elect policymakers who represent diverse interests, so that government will pursue broad objectives.

Whether representative democracy can deliver both high-ability politicians and broad representation is unclear. Visibly inept leaders are elected around the world. Moreover, economic models of politics hold that lower opportunity costs give the less able a comparative advantage at entering public life (Caselli and Morelli, 2004) and that this effect may be compounded by free-riding incentives (Messner and Polborn (2004), see also Olson (1965)). But even if it is possible to select competent politicians, doing so may make it harder to ensure broad representation when competence is unequally distributed. Related to this, a number of scholars have argued that electoral systems shape the tradeoff between accountability - a driver of selection and representation. ${ }^{2}$

To better understand political selection, and the potential tradeoffs it entails, we need to thoroughly describe selection patterns and analyze their determinants. Unfortunately, insufficient data has made it difficult to carry out these tasks.

Three data limitations First, any study of political selection should account for candidate entry and screening by voters or parties. To study candidate screening, one needs information on both elected and non-elected politicians. While information on the former is sometimes available, information on the latter is remarkably sparse. A few studies have tried to tackle this limitation to advance our knowledge of candidate selection. ${ }^{3}$ Unfortunately, this literature does not address candidate entry, which requires information on those who never attempted to enter into politics.

1. See for example Osborne and Slivinski (1996), Besley and Coate (1997), Pande (2003), Chattopadhyay and Duflo (2004), Jones and Olken (2005), Washington (2008), Besley et al. (2011), Meyersson (2014).

2. A common idea is that plurality rule fosters better accountability, while proportional representation fosters better representation (Myerson, 1993; Persson and Tabellini, 2003; Powell, 2000; Taagepera and Shugart, 2000).

3. Examples include: Besley et al. (2005), Ferraz and Finan (2009), Galasso and Nannicini (2011), Beath et al. (2014), Jia et al. (2015), Tillmann (2014), Folke and Rickne (2016). 
Second, the relevant theory stresses the quality of selected politicians. But how to measure quality? Absent direct data on the underlying intelligence or personality of politicians, the existing empirical literature has relied on education or pre-office income (Bäck and Öhrvall, 2004; Dal Bó et al., 2009; Ferraz and Finan, 2009; Merlo et al., 2010; Galasso and Nannicini, 2011; Besley and Reynal-Querol, 2011; Gagliarducci and Paserman, 2012). While correlated with ability, these proxies also likely reflect luck or social class.

Third, representation is hard to measure. Previous work has relied on measures like occupation. However, occupation is coarse: many politicians may be lawyers, but if values and loyalties depend on social background, one would like to know if they were brought up as elite or working class. This requires difficult-to-obtain intergenerational information.

In sum, we know of no research that analyzes selection based on a comprehensive bundle of traits that accurately reflect the ability and representativeness of politicians.

Sweden as a test bed Our study overcomes these limitations by using fine-grained administrative data from Sweden. Clearly, conclusions based on evidence from a single country cannot be extrapolated to the rest of the world, though we take a (very limited) step towards comparisons by studying different Swedish jurisdictions. But Sweden is of interest for both its commonalities and differences with other countries. Its politics is based on proportional-representation elections, the most common form in the world. Sweden is also a quintessential advanced democracy. It has remained stable and fully democratic with a top score on the 20-step Polity-IV scale since 1917, a full century during which other states gradually moved towards democracy. Sweden is thus an institutional exemplar many countries around the world may be approaching. When debating the value of democracy it is natural to ask if a democratic transition can improve the ability and representativeness of leaders. If Sweden displayed incompetent and unrepresentative leaders, advocates of democratization may have to resort to different arguments.

Data Our data allow us to undertake the most thorough description to date of basic political selection patterns based on rich measures of individual ability and social background. The ability measures include evaluations of IQ and leadership potential for the 1951-1980 cohorts, done by the military on all males, and an estimate of individual earning capacity for the whole population stemming from a fully saturated Mincer regression developed by Besley et al. (2016). Our social-background data entail reliable intergenerational information, namely social class as reflected in 
parental incomes and occupations (a traditional approach in sociology).

We study not only national members of parliament (MPs), but also politicians in municipalities - which provide the bulk of public services - to take advantage of large numbers and within-country variation.

Positive selection? We uncover new statistics on political selection for Sweden as a whole. Standard models of occupational choice predict adverse selection: able people with higher private incomes and more promising careers face a higher cost to enter public life. Nevertheless, we document strong positive selection along all ability measures even though politicians have substantially higher pre-office incomes - hence, higher opportunity costs - than the general population. Selection monotonically improves from those nominated (but not elected) to municipal council, to rank-andfile elected municipal council members, to mayors, and finally to MPs. Mayors and MPs are as positively selected as members of elite occupations in the private and public sectors.

Elitism vs. meritocracy? In a world where ability correlates positively with socioeconomic status, the strong positive selection we document could reflect very different regimes. One possibility, "elitism," is that rich families have privileged access to political power. Then, selection based on privilege will yield an accidentally competent political class. Another possibility, "exclusive meritocracy," is that politics selects the competent, which makes the political class (accidentally) elitist. The third possibility, "inclusive meritocracy," is that politics selects competent politicians broadly representative of all social backgrounds.

To determine which one of these regimes prevails, we ask whether political selection is driven mostly by social origin or by individual traits. Politicians turn out to be positively selected, not only relative to the population, but also relative to their own siblings who share their social background. This strong role for individual ability rules out the pure elitist regime. To discriminate between different meritocracies, we examine the social origin of politicians. While politicians themselves are disproportionately high-earning, their parents' social class and earnings approximate a perfect replica of the entire population. This pattern does not look accidental: different political parties represent different segments of the income distribution in a way that reflects their policy stance.

How is inclusive meritocracy achieved? Swedish politics attracts competent people who are not restricted to the scions of elite families. Two facts could conspire against this outcome. First, competence correlates positively with social class, so 
one should expect a tradeoff between competence and broad representation. Second, politicians have high pre-office earnings and the higher opportunity costs should push toward adverse selection on competence. How can inclusive meritocracy emerge? We answer this question in two ways. First, although ability rises with socioeconomic status on average, politicians remain highly able when recruited from low socioeconomic backgrounds. In fact, relative to their own social class, politicians from lower social backgrounds are even more strongly selected than politicians from higher social backgrounds. This mitigates the tradeoff between competence and representation. Second, an analysis of party screening and individual incentives to self-select into politics yields some suggestive take-aways. Parties appear to screen positively, promoting more competent individuals to higher ranks regardless of their social class. In addition, pecuniary considerations appear to matter for self-selection decisions, but a combination of strong intrinsic motivation and high wages for full-time positions preserves the incentives of able individuals to enter politics.

Organization of paper In the next section, we offer background information on the Swedish political system. Section 3 describes our data and their sources. In Section 4, we present results on political selection in terms of competence. In Section 5, we explore the social background of politicians and characterize Swedish politics as an inclusive meritocracy where selection on competence goes together with broad social representation. Section 6 briefly discusses the drivers of inclusive meritocracy: how competence and inclusivity go together, and forces shaping selection such as individual incentives and party screening. Section 7 concludes. Auxiliary material is collected in an Online Appendix.

\section{BACKGROUND}

Sweden's electoral system Sweden has three administrative levels of government. Every four years (three years prior to 1994), elections are run for 290 municipalities, 20 counties, and the nation. All elections take place on the same day with a turnout between 80 and 90 percent. In each election, citizens cast a separate party ballot, a ranked list with a large number of candidates. This system elects a total of 349 MPs, 1,100 county-council members, and 13,000 municipal-council members. Our paper is focused on the first and third groups.

In Sweden's proportional-representation (PR) system, seat shares in the municipal councils and the national parliament closely trace the vote shares of political parties. Until 1998, seats for each party were allocated from the top of the ballot. 
Since 1998, voters can also cast an optional preference vote for one candidate. But this reform has only allowed a handful of politicians from lower ranks to bypass the party's list order and win a seat. ${ }^{4}$

Based on the distribution of council or parliament seats, a ruling majority (or minority) is formed. These often form within the left bloc (Social Democrats, Left Party, and Green Party) or the center-right bloc (Conservatives, Center Party, Liberal Party, and Christian Democrats). Occasionally, the largest local party in a municipality wins more than half of the seats and rules on its own. In our time period, two anti-immigration parties (New Democracy, in the 90s, and Sweden Democrats, in the 00s) have also been represented, but these are rarely part of governing majorities. Local parties (running only in one municipality) also exist, but usually hold less than 5 percent of the seats.

Members of parliament (MPs) All members of the national parliament are full-time politicians, who spend much of their time in the parliament's various committees. The members are elected to office in one of 21 constituencies, where most of the members still have their residence. They are nominated on the constituency ballot of their political party, often after an earlier career in municipal politics. Among the parliamentarians elected in 2010, 72 percent had been elected to a municipal council for the same party at some point after 1982.

Municipal governance The council is the only directly elected body in each municipality. It has a board - the local analog of the national cabinet - to which members are appointed by the governing coalition to mirror the seat distribution. The largest party in the coalition selects the chair: henceforth, the "mayor." The political opposition usually appoints an executive as well, the "vice mayor."

The mayor holds an important office: municipalities play a crucial role as service providers in the economy, spending about 25 percent of Sweden's GDP and employing 20 percent of its workforce. Municipal politicians are responsible for the areas of K12 education, child care, elderly care, and local infrastructure, and finance these commitments through a local income tax of around 20 percent. Being a mayor (or a vice mayor) is thus commonly seen as a more influential and prestigious position than a common member of the national parliament, not only in the major cities of Sweden but also in mid-size municipalities. ${ }^{5}$

4. This reflects voter "abstention" from the optional vote, a concentration of votes for candidates at the top of the ballot, and high thresholds. See Folke et al. (2016) for a thorough analysis of the preference-vote system and its consequences.

5 . This is often borne out by revealed preference in the choices by politicians. Zetterberg (1988) 
Ruling over the Swedish welfare state used to be a Social Democratic prerogative. But in the past few decades, political competition has grown substantially more intense. This can be illustrated by the changing proportion of left-bloc local governments over time: it increased from 31 percent in 1991 to 73 percent in 1998, only to fall back down to 59 percent in 2002 and 41 percent in 2006.

Running for local office Depending on municipality size (from 2,558 to 780,817 inhabitants), local party members are divided into "clubs," like the women's and youth clubs. A citizen who enters politics becomes a party member and joins one or several clubs. All routes to office go through existing parties (short of forming a new party). Local parties compose their municipal electoral ballots without interference of the central party. A local political career may reach the top of the local party hierarchy - for the largest majority and minority parties, becoming mayor or vice mayor - or in a few cases a national parliamentary seat.

Sweden has a strong normative tradition of so-called "leisure politicians", where local political service is a spare-time activity complementing one's work in the regular labor market. Consequently, almost all elected council members receive only piecerate compensation for time spent in meetings. ${ }^{6}$ Previous research has also shown no indirect monetary gains to winning a seat in a municipal assembly (Lundqvist, 2013). But the mayor is a full-time political employee, and in most municipalities the vice mayor also gets a part-time salary. The mayor's wage, determined by the municipal council, is typically in the top 5 percent of the Swedish earnings distribution. Beyond this economic return, becoming a mayor is associated with high social status and substantial political power.

Monetary costs to running for local office are minimal. All candidates run on a party ballot, and campaign finance is mostly paid by tax money channeled to parties rather than candidates. Individual campaigns for preference votes are modest, with the vast majority spending less than 600 USD at the municipal level. Even these small costs are usually paid by the party or by outside donors, rather than by the individual herself (SOU, 2007).

A qualitative literature on Swedish politics suggests that key motives to enter pol-

makes a general case, and specific instances have been reported, for example in the mid-size municipalities of Falun (Sveriges Radio, 2006), Landskrona (Helsingborgs Dagblad, 2006), and Söderhamn (Hela Hälsningland, 2010).

6. This part-time arrangement may at first seem odd to the reader. However, part-time political service is quite common throughout the world. For example, state legislators in a number of US states only serve around half time on average with quite a modest compensation - see http://www.ncsl.org/research/about-state-legislatures/full-and-part-time-legislatures.aspx 
itics are intrinsic concerns with policy, or a desire for social interaction in policy circles (Karlsson, 2001). However, pecuniary concerns are also present, especially when experienced leisure politicians contemplate full-time appointments (Dahl, 2011).

Voter preferences and selection Swedish citizens value a competent and socially representative political class. When asked about their party choice, voters have ranked politician competence among the top three reasons for the past decades, along with ideology and issue voting (Statistics Sweden, 2010). When asked about what social dimensions merit influential positions, voters rank gender fist, closely followed by age, social group, and geographic area (Djerf-Pierre and Niklasson, 2010).

As for representation, left-bloc parties traditionally represent blue-collar workers, while center-right parties represent white-collar workers. In a recent survey of newly elected politicians, 48 percent of Social Democrats saw themselves as working class, and 42 percent as middle class. Among Conservatives, 5 percent saw themselves as working class, 42 percent as middle class, and the rest as upper class. Outside these two large parties, the Center party has traditionally represented farmers and people in rural areas. Within parties, social representation is advanced via strategies to increase representation of women, foreign-born, and the young (Freidenvall, 2006).

\section{DATA}

To characterize political selection, we assemble (to our knowledge) the most detailed and comprehensive data set to date. In this section we briefly summarize our sources, key variables, and sample definitions.

Sources Our empirical analysis is based on individual-level data from various sources. Our first dataset contains all elected and non-elected individual candidates that ran for national or municipal political office during the period of 1982-2010, over 200,000 unique individuals. Prior to each election, each political party must report its ordered list, with a personal identification code for each listed politician. These lists are kept by Statistics Sweden and, in some cases, regional electoral authorities. After each election, another record is created with a complete list of all elected politicians from each party. Altogether, our sample has roughly 50,000 elected individuals.

We link these data on politicians to several administrative registers from Statistics Sweden for the whole population (aged 16 and above). For most variables, our data hold annual records from 1979 to 2012 for the entire population, approximately 14 million unique men and women. These data contain detailed demographic and 
background information (e.g., age, sex, education level, and occupation), as well as earnings. Given this information, we can precisely characterize how the personal traits of politicians relate to those in the entire population.

We use the Multigenerational Register to identify siblings and parents. We use only biological parents and, as the data begin in 1979, we face a natural truncation. Nevertheless, for politicians elected after 2000, we observe the father's income in 1979 for 77 percent of the sample, and the mother's income for 86 percent of the sample.

Various types of annual earnings for the entire population are available from the Swedish Tax Authority. We also have universal annual information about individual sector of employment for the whole period. However, occupation is only recorded on a yearly basis from 2003. To bridge this gap, we complement the occupation data with earlier information from Censuses (done every five years).

Our last piece of individual-level data come from the Swedish Defense Recruitment Agency. Military enlistment tests measure the mental capacities of Swedish men (see further below). Although a mandatory draft was instituted in 1901, full records are only kept for cohorts born 1951 and onward. For quality reasons, we also truncate the data for men born after 1980. For these 30 cohorts, enlistment rates were around 90 percent.

Electoral results are linked to our dataset at the municipal level from records kept by the Swedish Electoral Agency. These give us the vote shares for every party in every election. Data on the party that appointed the mayor was obtained from Kfakta, a database collected by Leif Johansson (Department of Political Science, University of Lund).

The enlistment procedure The enlistment process for military service spans two days and evaluates a person's medical status, physical fitness, and cognitive abilities. About 75 percent of the men in our sample who took the test did so at 18, while about 25 percent took it at 19 (less than 0.5 percent were below 18 or above 19). Since enlistment generally occurs in the year of high-school graduation, test scores are not influenced by university training. As tests were high-stakes - better results gave more rewarding military placements - data quality is considered high. Takers were not informed of their precise results.

We use two scores from the enlistment procedure - the cognitive score and the leadership score. Each of these is standardized to a scale from 1 to 9 .

Cognitive score Cognitive ability is scored from a written test, assessing ability in problem solving, induction capacity, numerical, verbal, spatial, and technology 
comprehension (Ståhlberg-Carlstedt and Sköld, 1981). Army expert Berit Carlstedt (2000) argues that the Swedish enlistment test is a good measure of general intelligence. This differentiates it from others, such as the US Armed Forces Qualification Test, which focuses more on "crystallized" intelligence, i.e., teachable skills. We can thus think of the cognitive score as an IQ score. The (stanine) scale is such that a 5 is reserved for the middle 20 percentiles of the test population, while 6,7 , and 8 , are given to the next 17, 12, and 7 percentiles, and the top score of 9 to the uppermost 4 percentiles (scoring below 5 is symmetric). ${ }^{7}$

Leadership score Individuals who score a 5 or higher on the cognitive test go through an in-depth evaluation for a possible military leadership position. Trained psychologists administer a semi-structured interview to determine a 1-9 leadership score. Before the interview, the psychologist sees information about the conscript's cognitive test, physical endurance, muscular strength, school grades, and answers to 70-80 questions about friends, family, and hobbies, etc. The exact interview manual is classified information, but the test is known to evaluate a conscript's personality in civilian life, and his ability to handle military functions. Specifically, the score summarizes four personality traits: social maturity, psychological energy, intensity, and emotional stability. These are closely related to the well-known Big-5 personality traits (extraversion, consciousness, openness, conscientiousness, and neuroticism) see the Online Appendix, Table B.1.

Education Educational attainment of all individuals is reported by Swedish schools and universities, and records are kept by Statistics Sweden. For people migrating into Sweden later in life, information on schooling is collected through surveys and education levels are categorized into a Swedish standard. These categories are easily translated into years of education.

Income We use a measure of annual disposable income, constructed from individual tax records (there is no joint family taxation) including all income sources and government transfers (wages and in-kind benefits from jobs, pensions, transfers and subsidies, business income, capital income, sickness and parental-leave benefits, etc.).

7. In terms of standard deviations, scores translate as follows 1: below $-1.75,2:-1.75$ to -1.25 , 3: -1.25 to $-0.75,4:-0.75$ to $-0.25,5:-0.25$ to $0.25,6: 0.25$ to $0.75,7: 0.75$ to $1.25,8: 1.25$ to 1.75 , and 9: above 1.75. 
Earnings score If ability is priced in the market, it shows up in earnings. Earnings may also reflect a number of other personal characteristics, however, such as education, choice of employment, or time and place of employment. To get at a measure of relative earnings power that more likely reflects personal ability, we construct an earnings score following the approach of Besley et al. (2016). These authors use residuals from a Mincer equation, defined over a large set of socioeconomic characteristics. As estimating a fully saturated model with millions of observations is computationally challenging, we estimate the Mincer equation year by year. Specifically, we estimate:

$$
y_{i, m, t}=f\left(\text { age }_{i, t}, e d u c_{i, t}, e m p l_{i, t}\right)+\alpha_{m}+\varepsilon_{i, m, t},
$$

where the dependent variable $y_{i, m, t}$ is the disposable income for person $i$ in municipality $m$ in year $t$. Among the independent variables, $a g e_{i, t}$ is a set of age indicators (over 5-year intervals), $e d u c_{i, t}$ is a binary indicator for tertiary education, and $e m p l_{i, t}$ is a set of indicators for 15 activity codes. ${ }^{8}$ The function $f$ represents a full set of ageeducation-employment interactions. The regression also includes municipality fixed effects $\alpha_{m}$ to capture systematic income differences across regions, or urban and rural areas. This flexible specification allows for different age-earnings profiles across occupational sectors and education levels. For each individual, we compute residuals $\varepsilon_{i, m, t}$ for each available year, and then average across years. This "individual fixed effect" is our earnings score.

To minimize measurement error and endogeneity, we drop observations for fulltime politicians, both in office and after exiting office. We estimate equation (1) separately by gender and retirement status (age over 65 or not) in order not to confound the competence measure with the substantial labor-market differences across these groups. ${ }^{9}$

8. These are the same as the European NACE code and international ICIC code, namely: "Agriculture, hunting and forestry," "Fishing," "Mining and quarrying," "Manufacturing," "Electricity, gas and water supply," "Construction," "Wholesale and retail trade; repair of motor vehicles, motorcycles and personal and household goods," "Hotels and restaurant," "Transport, storage and communication," "Financial intermediation," "Real estate, renting and business activities," "Public administration and defense; compulsory social security," "Education," "Health and social work," and "Other community, social and personal service activities." Two categories, "Activities of households" and "Extra-territorial organization and bodies" have less than 30 individual-year observations in them. Because of this, we add the former to "Other community, social and personal service activities," and the latter to "Public administration and defense; compulsory social security."

9. For example, women take on the bulk of parental leave and care activities that raise the gender pay gap when couples have children. As for retirement, there are plenty of senior politicians. Mincer equations of retired and working people differ as retirees do not have a current employment sector. 
Does the earnings score measure a competence for politics rather than just ability to generate market income? Besley et al. (2016) address that question and show that earnings scores are indeed correlated with cognitive and leadership ability as well as various measures of political and policy success.

Summary statistics Table I reports means of the four ability variables for politicians and the entire population (subject to availability), pooling the election years of 1991, 1994, 1998, 2002, 2006 and 2010 (the patterns we document below remain current: they do not change if we focus on the most recent year). In order to account for the fact that politicians of different quality may serve for different lengths of time, affecting the composition of the political class, an individual politician's observation is included as many times as he/she was elected. For municipalities, we distinguish between the nominated (but non-elected), elected, and mayors. We also include information on national MPs. Compared to the population, Swedish politicians under-represent women and the foreign born. Of mayors, less than 30 percent are women and less than 3 percent foreign born. We do not address these important forms of under-representation any further. But the most striking point of the data is a main topic in our analysis: Swedish politicians are positively selected based on all four ability measures. The progression of mean cognitive and leadership scores from nominated to elected to mayor to MP suggests increasing rates of positive selection.

[Table 1 about here]

Table B.2 in the Online Appendix shows pair-wise correlations between our competence measures for the Swedish male population in 2011. All measures are positively correlated, but not very highly. Years of schooling has correlations of $0.51,0.30$ and 0.076 with the cognitive, leadership, and earnings scores, respectively. While the best measure of competence is an open issue, these simple correlations highlight the hazards of relying solely on years of schooling as a metric of ability. The leadership score and the cognitive score have a correlation of 0.34 , and the earnings score has correlations of 0.20 and 0.17 with the leadership and cognitive scores, respectively. Our different measures thus appear to capture different dimensions of ability.

We compute the income residuals of retirees based on the main sector of employment in their working-life. 


\section{Competence}

In this section, we rely on the universe of municipal and national politicians to answer the question whether selection on competence is positive or - as theory would have us expect - adverse. Our first contribution is to compare the ability characteristics of politicians to those of the general population. We study the four different ability dimensions introduced in Section 3. To repeat, the education and earnings scores are available for the full population, while the cognitive and leadership scores are available only for men.

Leadership and cognitive scores The top-left graph in Figure I shows overlapped histograms for the leadership scores of the general (male) population, three categories of municipal politicians - nominated but not elected, elected, and mayors - and MPs. A clear pattern of positive selection emerges. Leadership scores of the nominated look quite close to those of the population but with a slight shift to the right - scores above the population mean of 5.3 are more highly represented among nominated politicians than in the general population. ${ }^{10}$ For elected politicians, the shift to the right is stronger, and even more so for mayors and MPs. For example, mayors have more than a full additional point - 70 percent of a population standard deviation - higher leadership scores than the population (henceforth, $\sigma$ denotes a population standard deviation).

\section{[Figure 1 about here]}

The top-right graph shows a similar result for the cognitive score. Politicians score higher than the average Swede, more strongly so when elected to office, and particularly so when selected for top-municipal office and parliament. Mayors score 1.3 points $(0.68 \sigma)$ higher than the average person, while MPs score 1.6 points (around $0.84 \sigma$ ) higher than the average person.

Earnings scores The bottom-left graph in Figure I displays the distributions of the earnings score. The nominated display a small shift to the right - their mean score is higher by $0.19 \sigma$. The elected show a clearer shift, with a $0.58 \sigma$ difference. The earnings score of mayors and MPs surpass that of the population by a full $\sigma$, and $1.4 \sigma$, respectively.

10. Because of the large sample, all differences across groups reported in this subsection are strongly statistically significant, with p-values below 0.001. A similar pattern holds in other sections of the paper unless noted otherwise. 
The earnings score evidence is important for three reasons. First, it includes both females and males. The strong positive selection is present for both genders and, if anything, female politicians are more strongly selected than males, especially at higher offices like mayor and MP (see Figure A.1 in the Online Appendix). Second, strong positive selection on intelligence and leadership alone might just reflect a lower opportunity cost for those who become politicians. But the opposite seems to be true: politicians have higher earnings scores as well as actual (pre-office) earnings - see Figure III below. Third, previous empirical work that proxies politician qualifications through education reports high levels of achievement, at least for mayors and national legislators, easily above the general population. ${ }^{11}$ But if access to higher education merely reflects elite membership, then educational attainment becomes a poor marker of positive political selection. Our earnings-score results show positive selection even after conditioning on education level and sector of employment.

Education The distribution of education attainment over seven levels (in the bottom right of Figure I) shows a similar pattern, with politicians under-represented at the bottom levels, and over-represented at higher levels. As reported in Table I, the nominated have one more year of education than the average Swede, while elected politicians and mayors have roughly an additional year and a half. MPs have almost three years of schooling above the population average. In the remainder of the paper, we focus on the three non-education measures of competence.

The key takeaway from these graphs is a strong pattern of positive selection in Swedish politics, which gets more positive at higher political ranks. This flies in the face of the argument that the more competent are less likely to enter politics due to higher opportunity costs, and shows that incompetent politicians are less common as leadership positions become more important.

Politicians vs. high-status professions To gain an additional perspective on selection, we also compare politicians to members of Swedish elite occupations known for attracting talented people. Table II shows our competence measures, as well as earnings, for the four categories of politicians, CEOs, lawyers, medical doctors, and academic social scientists. The positive selection among CEOs increases with company size. Elected politicians have cognitive and leadership scores similar to CEOs with 10-25 employees, a group which is also comparable in size. Mayors have

11. See for example Ferraz and Finan (2009) on Brazilian mayors, Merlo et al. (2010), Galasso and Nannicini (2011) and Gagliarducci and Paserman (2012) on Italian legislators, Dal Bó and Rossi (2011) on Argentine legislators, or Dal Bó et al. (2009) on U.S. legislators. 
exactly the same scores as CEOs in companies with 25-250 employees, even though mayors earn substantially less. Parliamentarians have leadership and cognitive scores in between CEOs in companies with 25-250 employees and those in companies above 250 employees. Lawyers and academic social scientists outscore CEOs and mayors in terms of cognitive ability. Medical doctors - a highly prestigious profession in Sweden associated with excellence - clearly show the highest cognitive scores of all. Academic economists and political scientists have the most years of education, rank second and third in cognitive scores, but have among the lowest leadership scores.

[Table 2 about here]

The patterns in the table make intuitive sense. Academics are smart, but lack leadership, and as a result they accumulate the most years of education, but neither lead organizations nor make life-or-death decisions. Mayors, MPs and CEOs are marginally less smart, substantially less educated, but have higher leadership scores and, fittingly, do lead public and private organizations.

Positive selection beneath the aggregate Although we find evidence of strong positive selection in the aggregate, one may be concerned that this is an artifact of the selection patterns of a few large municipalities. To examine this possibility, we compare the traits of elected politicians to those of the average person in their respective municipalities. Overall, few municipalities exhibit negative selection, and the vast majority of municipalities select positively: 96 percent of municipalities on the cognitive score, 86 percent on the leadership score, and more than 99 percent on the earnings score. In Dal Bó et al. (2016), we provide a more detailed analysis of the selection patterns across municipalities.

\section{Social Representation}

Section 4 showed a strong positive selection of politicians, and increasingly so at higher political office. But this pattern could reflect very different selection regimes. Perhaps Swedish politics is elitist rather than meritocratic, with heirs of rich families getting privileged access to political power as well as to education and earning opportunities. Under such "elitism," the competence of politicians is a side effect and does not play a preeminent role in selection. Under the elitist regime, elite membership by itself (due to wealth or connections, for example) determines selection. The empirical implication (i) is that, conditional on elite status, individual ability should matter little for selection. Alternatively, under "exclusive meritocracy," those from 
more advantaged social classes still acquire stronger abilities, but it is those abilities rather than privilege that helps them enter politics. This regime is compatible with individual ability shaping selection, but it also implies (ii) that social background is strongly associated with selection.

In this section we establish that Swedish reality is better described by a third regime: "inclusive meritocracy." In this account positive selection on competence goes together with inclusive social representation. We establish the presence of inclusive meritocracy in two steps. In the next subsection we show the elitist account is untenable; we falsify the above-mentioned empirical implication (i), by showing that even when conditioning on family (and hence, social) background, individual ability matters greatly for selection. In the following subsection V.B. we falsify empirical implication (ii) by showing politicians represent all social backgrounds.

\section{V.A. Elitism or meritocracy?}

In this subsection we study political selection by holding constant the social background of politicians. To do this, we compare the individual characteristics of politicians not just against the population, but against their own siblings.

Politicians and their siblings Figure II compares the distribution of competence traits of elected politicians with that of their siblings. To ease comparison with Figure 1, we also include the full population distribution. Clearly, elected politicians have markedly higher cognitive and leadership scores than their siblings, as well as higher earnings scores.

We can also compare the extent of selection between politicians and siblings to that between politicians and the population. The difference vs. siblings for leadership scores is equal to 78 percent of the gap vs. the population - for cognitive and earnings scores, the respective numbers are 70 and 74 percent. These numbers strongly indicate that ability, and not family background, is the key selection criterion. ${ }^{12} \mathrm{~A}$ similar look at mayors and MPs in Figure II confirms that politicians at higher levels are also drawn from a different ability distribution than their siblings.

[Figure 2 about here]

Figure III further illustrates how individual traits beyond family background shape political selection. It classifies politicians by their percentile in the income

12. Although politicians tend to be born first more often than their non-politician siblings, this difference in birth order does not explain the pattern in Figure II. Our ability measures are only marginally different for first-born versus later-born. 
distribution, compared to the population in their own birth cohort and gender. By definition, the population would display a perfect uniform distribution with a density of 0.05 for each 5-percentile bin. The left graph in each row shows that politicians (elected, mayors and MPs) are disproportionately drawn from higher income percentiles. (Incidentally, but also importantly, this indicates that more able people face higher opportunity costs from entering politics, which would encourage adverse selection.) But the distribution in the right panel for politician siblings is much more similar to the uniform population distribution.

\section{[Figure 3 about here]}

Overall, these patterns indicate that an individual's own ability traits matter for his/her political fortunes, and rule out the pure elitist account.

\section{V.B. Inclusive meritocracy}

Politicians and their parents Next, we directly examine the relevance of social background, and show that it does not matter much for aggregate political selection. Measuring social background by parental income and occupational status (see below), we find that politicians do not come disproportionately from elites. ${ }^{13}$

For politicians in the most recent decade of our data, we find their parents' incomes and occupations in the earliest year(s) of our data. ${ }^{14}$ We use the full population data to allocate individuals into bins comprising five percentiles of the annual-earnings distribution within each gender and birth year. We then compute the proportion of fathers of politicians with 1979 incomes within each 5-percentile bin. ${ }^{15}$ These proportions are shown in the top row of Figure IV. Recall from the first column of Figure III that for politicians own incomes these distributions are

13. Summary statistics for parental incomes together with the four competence measures and the measures of social class appear in the Online Appendix Table B.3.

14. As stated before, for politicians elected after 2000, we observe the father's income in 1979 for 77 percent of the sample, and the mother's income for 86 percent of the sample. For those elected in 2010 we match over 90 percent of politicians. Since the match is less than perfect, one might be concerned about sample selection bias. Compared to the matched politicians, the politicians whose fathers' 1979 income are missing tend to be slightly less competent, although only differences in education levels and cognitive scores are statistically significant. It is reasonable to assume that the fathers of these unmatched politicians came from lower social classes, since ability is largely hereditary and positively correlated with social class. Then we are underestimating the share of politicians that come from humbler origins, a bias which works against finding broad representation.

15. In the uncommon cases that a father has multiple children who become politicians, that father's observation is included as many times as offspring-politicians he produced. 
skewed to the right reflecting a striking over-representation of high earnings. But for the same politicians' fathers, the distribution has a much more uniform shape. This is true especially among elected councilors, whose fathers are almost perfectly representative of the population. (The corresponding figure for mothers' earnings can be found in the Online Appendix, Figure A.2.) A similar - albeit less perfect - pattern of broad representation of parental backgrounds is present among mayors and MPs.

[Figure 4 about here]

Politicians, CEOs, and medical doctors Again, it is valuable to compare politicians with other elite professions. To do so, the bottom row of Figure IV repeats the same exercise as in the top row, but for fathers of medical doctors (left graph) and CEOs of firms with different size (two right-most graphs). These figures show that the 1979 earnings for fathers of doctors and CEOs are much more skewed to the right than the earnings for fathers of politicians, especially for doctors and large-company managers. Naturally, the earnings of the doctors and CEOs themselves (not shown) are also very much skewed to the right.

We can summarize the evidence from Figure IV in a different way. As measured by intergenerational earnings, social mobility into a political career seems to be high in absolute as well as relative terms, when compared to doctors and CEOs.

Politicians in different parties The evidence so far concerns elected politicians from all parties. In Figure V, we replicate Figure IV for those elected to municipal councils in the three largest parties, the Social Democrats, the Conservatives, and the Center (agricultural) party. As the left column shows, politicians in all parties come disproportionately from the top part of the income distribution, though more so in the Conservatives than in the Social Democrats or the Center party. In the three right graphs, however, we clearly see representation of different social backgrounds. Highincome earners are over-represented among the fathers of Conservatives and middleincome earners among fathers of Social-Democrats. Finally, low-income earners are overrepresented among fathers of Center-party politicians, who are often farmers (on average, 40 percent as opposed to 5 percent in other parties) with relatively low earnings.

[Figure 5 about here]

Figure V makes clear how parties represent different parts of the (parental) income distribution. The aggregation of these diverging party representations renders the 
almost perfect representation of parental incomes in the top left panel of Figure IV for all elected municipal politicians. Of course, this illustrates the presumption that different parties represent different interests - at least in polities with a multi-party system where the left-to-right dimension is important.

Social class While informative, parental income only captures one aspect of social status. Thus, we also consider data on parental social class as determined by occupational status whenever this information is available. Figure A.3 in the Online Appendix compares distributions of social class for politician parents and the population. ${ }^{16}$ That figure corroborates our previous finding: politicians are highly representative of the population. The only notably over-represented social class is farmers, which reflects the historical role of the Center party. We also see some under-representation of skilled manual workers.

As argued earlier, if parental human-capital investments shape individual competence, a strictly meritocratic system might still favor elites. Meritocracy could then favor the competent within a family, but still be elitist across families as per the exclusive-meritocracy description. However, our finding that different social classes are evenly represented rejects this interpretation. Instead, Sweden's political system is both meritocratic and broadly representative, as per the inclusive-meritocracy description.

\section{DRIVERS OF COMPETENCE AND REPRESENTATION}

In this section we address potential drivers of Sweden's inclusive meritocracy. Two facts stand in the way of such a regime. First, (as we will document) ability correlates positively with social class. Thus one might expect competence to be in tension with inclusivity. Second, more able people have higher earnings and hence face higher opportunity costs. This should make positive selection on competence difficult in the first place. The first subsection examines whether there are signs of a tradeoff between competence and inclusive social representation by examining

16. The class division corresponds closely to the EGP social-class scheme (Erikson and Goldthorpe, 1992) which has been used by Lindgren et al. (2016) in their recent study of representation in Sweden. We define six classes as: (1) non-skilled manual workers, (2) skilled manual workers, (3) lower non-manual workers, (4) farmers, (5) intermediate non-manual workers, and (6) higher non-manual workers. We are grateful to Martin Hallsten for sharing his STATA code with us. We are forced to drop the category of "self-employed" because of data constraints. The data are again from 1979, and 54 percent of the politicians nominated in 2010 have a father for which we can define socioeconomic status. 
cross-sectional patterns of municipal politicians. The second subsection examines patterns of selection by socioeconomic status in the aggregate. In that subsection we explain why there is only a weak tradeoff between competence and inclusivity, and why inclusive meritocracy is feasible. The third and fourth subsections answer the question of how is positive selection on competence feasible in the first place, given that the competent face higher opportunity costs.

\section{VI.A. Is there a competence-representation tradeoff?}

In order to characterize local selection and representation, we compare politicians in each council to their municipal population according to a simple index. Let $x$ denote either a measure of competence or social class with $K$ categories. We can write this index as

$$
S_{x}=\sum_{k=1}^{K} p_{k, c} k-\sum_{k=1}^{K} p_{k, m} k,
$$

where $p_{k, c}$ is the proportion of council members in each category $k$, and $p_{k, m}$ is the corresponding proportion in the municipal population. The intuition is simple. If the trait distribution in a municipality has support from 1 to 9 with a mean of 5 , and politicians are positively (negatively) selected on competence, their scores on average are higher (lower) than 5, giving a positive (negative) selection index. Analogously for the case of social class, when this index is zero for a municipality, all its social classes are represented among politicians in proportion to their population prevalence (or excess representation of lower classes balances out excess representation of higher classes). We use this index to gauge municipal selection along each of our ability variables - namely IQ, leadership, and earnings score - and social class variables standardized parental income or occupational status.

In Figure VI, we plot the relationship between competence and representation for our various indices. We also include the corresponding regression line, and the estimated slope coefficient for each of these six relationships. The estimated slopes are all positive, suggesting a tradeoff.

[Figure 6 about here]

But the slope coefficients are small. For parental social class, the strongest relationship suggests that a $1 \sigma$ higher over-representation of upper social classes is associated with a $0.15 \sigma$ higher cognitive score among elected municipal politicians. For the two other competence measures, the relationships are much weaker. For parental income, the strongest relationship suggests that a $1 \sigma$ larger over-representation of 
high parental income is associated with a $0.15 \sigma$ higher average earnings score. For the cognitive and leadership scores, the estimates are of even smaller magnitudes and not statistically significant. ${ }^{17}$ Overall, these correlations suggest a weak tradeoff between competence and social background.

\section{VI.B. Selection by socioeconomic background}

The flat tradeoff between competence and social representation shown in the last subsection may be surprising, given the problems to disentangle innate ability and parental background. Despite Sweden's comparatively uniform education system, parental background likely shapes measured ability via socialization and home resources. If (i) competence correlates positively with socioeconomic status, we should observe a steep tradeoff unless (ii) stronger positive selection compensates for lower averages in lower socioeconomic groups. To understand the flat tradeoff, and how inclusive meritocracy is feasible, we investigate statements (i) and (ii) by parental socioeconomic background.

Competence and socioeconomic status For each of our three ability measures, Figure VII plots the average ability for both the population and each category of politicians (nominated, elected, mayors, MPs) who belong in each quartile of the parental income distribution. The plot suggests that condition (i) holds: there is a positive relationship between parental economic background and ability in the population. For example, among citizens with parents in the bottom income quartile, average leadership scores are 5.1, versus 5.64 among those with parents in the top income quartile, a difference of about $0.3 \sigma$. The analogous inter-quartile distances for the cognitive and earnings scores are $0.45 \sigma$ and $0.16 \sigma$, respectively. ${ }^{18}$

[Figure 7 about here]

Ability selection by parental background The main reason why inclusive meritocracy is feasible, and why the tradeoff may appear flat, is that qualification (ii) holds: positive selection on ability is stronger in lower social classes, which mitigates

17. Admittedly, measurement error could be attenuating these estimates. While this is a potential concern, recall that we find support for an inclusive meritocracy even at the aggregate level.

18. The differences may be kept from becoming larger by the facts that the education system in Sweden is entirely financed by the public sector, that admission to higher education is entirely based on high-school grades, and that education traditionally has been provided in roughly equal quality across the country. 
the ability cost of recruiting politicians from those classes. Consider cognitive scores: politicians with fathers in the top income quartile outscore the general population with fathers in the same quartile by $0.39 \sigma$. But elected councilors with fathers in the bottom income quartile outscore the population with fathers in the same quartile by $0.50 \sigma$. Figure VII shows that this pattern is even more pronounced among mayors and MPs. If a politician of humble origin makes it that high, then that politician is very strongly selected. Online Appendix Figure A.4 shows similar patterns relying on father's occupational social class.

One striking aspect of these figures is the remarkable stability of positive selection out of all father's income levels and social classes. What defeats the tradeoff between competence and inclusivity is the fact that every class has competent people, and the strong positive selection washes out average ability differences.

\section{VI.C. Individual self-selection}

As shown before in Figure III, the competent face higher opportunity costs. How, then, are the competent attracted into politics? One possibility is that in Sweden pecuniary incentives do not matter. In this section, we further investigate the potential drivers of political selection with the guidance of a simple model of pecuniary and intrinsic incentives. The model and its predictions are presented in Section $\mathrm{C}$ of the Online Appendix.

Material vs. intrinsic motives In our model, material motives make wages in office, chances of accessing power, and age-earnings progression in a person's occupation relevant for selection. In the data, we indeed find evidence that material incentives help shape self-selection. The competence of top politicians is higher in municipalities with higher remunerations for mayors and vice-mayors, relative to municipal average earnings (Online Appendix Figure A.5). Also, the competence of top politicians is higher in parties with a higher probability of filling these full-time political positions (Online Appendix Table B.4). Lastly, politicians with occupations with steeper age-earnings profiles are less positively selected out of their own occupation than politicians with flatter age-earnings profiles (Online Appendix Figure A.6). This is not only consistent with the model's notion of opportunity cost. To the extent that the types of jobs held by parents and children are positively correlated, the finding also helps explain the better selection for politicians with low socioeconomic backgrounds discussed in the previous subsection. All three findings are consistent with material motives being relevant for political self-selection, which then re-emphasizes the question: how are the competent attracted into politics? 
Full-time political positions are very well paid in Sweden, which appears relevant given the evidence in Online Appendix Figure A.5. But politicians in local parties with close to zero probabilities to land full-time political jobs are still considerably smarter than the average citizens in the corresponding municipality (Online Appendix Table B.4). According to our simple model, this aspect of the data is only consistent with strong intrinsic motives to serve in politics.

\section{VI.D. Party Screening}

The next step in the Swedish selection process is that parties screen those individuals who self-select into politics. One way parties do this is by observing their members compete in coming up with good arguments and policy proposals. Such competition may well result in positive selection if more able politicians win out in the tournament and climb to the top of the party. Alternatively, party constituencies (e.g., the youth branch, the female branch, associated unions, etc.) can select and promote the more able to higher positions in the party list.

As mentioned in Section 2, qualitative work in political science suggests that Swedish political parties actively screen and promote candidates. While we do not strive to identify the exact mechanisms, we now present some quantitative evidence that parties gradually promote the more competent to higher positions.

Selection and list rank We consider all party lists in all municipalities, and all electoral periods within our sample. From these, we compute an ability index for all candidates with a certain list rank, for each rank between 1 and 8 . The left-column graphs in Figure VIII show how ability varies by rank for the cognitive score, the leadership score, and earnings score. Starting at the top (list rank 1), all measures more or less steadily decline as we move down the list, with the clearest pattern for the earnings score. In particular, the top-ranked politician has significantly higher ability than every other rank for all three ability measures.

Parties thus seem to screen and promote more able people towards progressively higher positions on their ballots. Given this positive screening, an improvement of those who self-select into political service will typically translate into higher competence of elected politicians.

[Figure 8 about here]

The middle-column graphs show the promotion patterns by socioeconomic background. In particular, the black (gray) dots refer to politicians whose fathers' incomes were below (above) the median. If anything, the competence-promotion gradient is 
steeper for politicians from lower social classes. Thus it seems that party screening is one of the mechanisms behind the broad representation we observe.

Finally, we might suspect that the motives for positive screening are stronger with stiffer political competition as measured by electoral win margins. The rightmost graphs in Figure VIII suggest that positive party screening is indeed stronger in municipalities with stiffer political competition (the gray dots).

All in all, healthy political parties - that can offer positive screening to society appear to be an important component of Sweden's inclusive meritocracy in politics.

\section{CONCLUSion}

Research in political economics offers theoretical arguments and empirical evidence for the notion that leaders matter, and that societies benefit from an able and broadly representative leadership. While democracy may be better suited than other political systems to promote representation, it is not clear that it can deliver both able and representative leadership. To shed light on this, we analyze political selection in Sweden, a paradigmatic advanced democracy. We use rich information on ability traits and social background for the universe of national and municipal politicians and the entire Swedish population.

We uncover four facts. (1) Politicians are strongly positively selected for all ability measures, despite their facing higher opportunity costs, with a monotonic relation between ability and political power. (2) Positive selection is present even conditional on social and family background: in other words, individual ability matters greatly for selection. (3) Representation of social background, whether measured by parental earnings or social class, is very even. (4) At most, there is a weak tradeoff in selection between ability and inclusive social representation.

Democracy can thus promote competent leadership, which stems from inclusive meritocracy, rather than from pure elitism or an exclusive meritocracy where the privileged have an upper hand. In Sweden, political parties attract the competent and promote the best to higher ranks, quite independently of social class. As a result, the Swedish system produces plenty of well-selected politicians from low socioeconomic backgrounds. While further research into this process is beyond the scope of our study, a few elements appear to matter. One is a combination of well-paid full time positions and strong intrinsic motivation to serve in uncompensated ones; another is party governance in reasonable health working within an electoral system allowing parties to represent various segments of society; and a third is availability of talent across social classes (which may, in turn, reflect universal high-quality education). 
Although we cannot easily extrapolate to the rest of the world, our four facts alleviate concerns that political systems encouraging broad representation necessarily select mediocre leaders. Some of the patterns we find may still be specific to Swedish political (and societal) institutions. Data permitting, it would thus be very interesting to carry out a comparative analysis of other countries with similar or dissimilar political systems.

Our findings suggest that we may have to rethink models of political selection and recruitment. Standard models, which focus on opportunity costs and material motives for holding office, cannot explain positive selection of the type we uncover. The data seem to support a richer view, where intrinsic as well as material motives shape entry into politics, and where screening matters. Political parties play an active role in screening candidates, and our results suggest that candidate ability is an important element in this calculus.

Future work should extend the analysis in several dimensions. There is room for more comprehensive modelling and testing of hypotheses on individual motives in self-selection (the supply of politicians) and on the precise ways parties and voters screen (the demand side). In addition, future research should attempt to quantify intrinsic motivation, and its impacts on selection and performance. Finally, it would be valuable to study how the competence and representativeness of political leaders leave a mark on policy outcomes. 


\section{REFERENCES}

Bäck, Hanna and Richard Öhrvall. Det nya seklets frtroendevalda: om politikerantal och representativitet i kommuner och landsting" (The new century's representatives: About the number of politicians and representativeness in municipalities and counties). Technical report, Justitiedepartementet (Department of Justice), 2004.

Beath, Andrew, Fotini Christia, Georgy Egorov, and Ruben Enikolopov. Electoral Rules and the Quality of Politicians: Theory and Evidence from a Field Experiment in Afghanistan. Working Paper 20082, National Bureau of Economic Research, 2014. URL http://www .nber .org/papers/w20082.

Besley, Timothy and Stephen Coate. An Economic Model of Representative Democracy. The Quarterly Journal of Economics, 112(1):85-114, 1997. URL http://EconPapers .repec .org/RePEc: oup:qjecon:v:112:y:1997: i : 1:p:85-114.

Besley, Timothy and Marta Reynal-Querol. Do Democracies Select More Educated Leaders? American Political Science Review, 105(3):552-556, 2011.

Besley, Timothy, Rohini Pande, and Vijayendra Rao. Political Selection and the Quality of Government: Evidence from South India. Center Discussion Papers 921, Economic Growth Center, Yale University, 2005.

Besley, Timothy, Jose G. Montalvo, and Marta Reynal-Querol. Do Educated Leaders Matter? Economic Journal, 121(554):F205-227, 2011. URL https://ideas.repec.org/a/ecj/econjl/v121y2011i554pf205-.html.

Besley, Timothy, Olle Folke, Torsten Persson, and Johanna Rickne. Gender Quotas and the Crisis of the Mediocre Man: Theory and Evidence from Sweden. Mimeo, Stockholm and Uppsala Universities, 2016. URL http: //EconPapers .repec .org/RePEc : hhs : iuiwop:0985.

Carlstedt, Berit. Cognitive Abilities. Aspects of Structure, Process and Measurement. Dissertation, University of Gothenburg, 2000.

Caselli, Francesco and Massimo Morelli. Bad Politicians. Journal of Public Economics, 88(3-4):759-782, 2004. 
Chattopadhyay, Raghabendra and Esther Duflo. Women as Policy Makers: Evidence from a Randomized Policy Experiment in India. Econometrica, 72(5):1409-1443, $2004 . \quad$ URL https://ideas.repec.org/a/ecm/emetrp/v72y2004i5p1409-1443.html.

Dahl, Svend. Efter folkrörelsepartiet: Om aktivism och politiska kursomläggningar $i$ tre svenska riksdagspartier (Life after the popular parties: About activism and political re-directions of three parties with parliamentary representation). Dissertation, Stockholm University, Stockholm Studies in Politics 140, 2011.

Dal Bó, Ernesto and Martín Rossi. Term Length and the Effort of Politicians. Review of Economic Studies, 78(4):1237-1263, 2011. URL https://ideas.repec.org/a/oup/restud/v78y2011i4p1237-1263.html.

Dal Bó, Ernesto, Pedro Dal Bó, and Jason Snyder. Political Dynasties. Review of Economic Studies, 76(1):115-142, 2009.

Dal Bó, Ernesto, Frederico Finan, Olle Folke, Torsten Persson, and Johanna Rickne. Who Becomes a Politican? Working Paper Series 1133, Research Institute of Industrial Economics, September 2016. URL https://ideas.repec.org/p/hhs/iuiwop/1133.html.

Djerf-Pierre, Monika and Birgitta Niklasson. Vem vill ha jämställdhet? (Who Wants Gender Equality?). In Holmberg, Sören and Lennart Weibull, editors, Det våras för politiken: trettiotvå artiklar om politik, medier och samhälle (Springtime for politics: thirty-two articles about politics, the media, and society. Oxford University Press, 2010.

Erikson, R. and J.H. Goldthorpe. The Constant Flux: a Study of Class Mobility in Industrial Societies. Clarendon Press, 1992. ISBN 9780198273837. URL https://books.google.com/books?id=WfYDAQAAIAAJ.

Ferraz, Claudio and Frederico Finan. Motivating Politicians: The Impacts of Monetary Incentives on Quality and Performance. NBER Working Papers 14906, National Bureau of Economic Research, Inc, 2009.

Folke, Olle and Johanna Rickne. The glass ceiling in politics formalization and empirical tests. Comparative Political Studies, pages 567-599, 2016.

Folke, Olle, Torsten Persson, and Johanna Rickne. The Primary Effect: Preference Votes and Political Promotions. American Political Science Review, 110(3):559578, Aug 2016. doi: 10.1017/S0003055416000241. 
Freidenvall, Lenita. Vägen till Varannan damernas. Kvinnorepresentation, kandidaturval och kvotering i svensk politik 1970-2002 (The road to "zippered lists". Female representation, candidate choice and quotas in Swedish politics 1970-2002). Technical report, Stockholms Universitet, 2006.

Gagliarducci, Stefano and M. Daniele Paserman. Gender Interactions within Hierarchies: Evidence from the Political Arena. Review of Economic Studies, 79(3):1021-1052, $2012 . \quad$ URL https://ideas.repec.org/a/oup/restud/v79y2012i3p1021-1052.html.

Galasso, Vincenzo and Tommaso Nannicini. Competing On Good Politicians. American Political Science Review, 105(1):79-99, 2011.

Hela Hälsningland. Rather Mayor than Parliamentarian (Hellre kommunalråd är riksdgsman), 2010. URL http: //www.helahalsingland.se/halsingland/soderhamn/hellre-kommunalrad-an-riksdagsman.

Helsingborgs Dagblad. Torkild Chooses Landskrona rather than Parliament (Torkild väljer Landskrona före riksdagen), $2006 . \quad$ URL http://www.hd.se/2006-05-02/torkild-valjer-landskrona-fore-riksdagen.

Jia, Ruixue, Masayuki Kudamatsu, and David Seim. Political Selection in China: The Complementary Roles of Connections and Performance. Journal of the European Economic Association, 13(4):631-668, 2015. ISSN 1542-4774. doi: 10.1111/jeea.12124. URL http://dx.doi.org/10.1111/jeea.12124.

Jones, Benjamin F. and Benjamin A. Olken. Do Leaders Matter? National Leadership and Growth Since World War II. The Quarterly Journal of Economics, 120(3):835-864, $2005 . \quad$ URL https://ideas.repec.org/a/oup/qjecon/v120y2005i3p835-864 . html.

Karlsson, David. Ny som förtroendevald i kommuner och landsting (New to Local Politics). In Att vara med på riktigt demokratiutveckling i kommuner och landsting (To participate for real - democratic developments in municipalities and counties). SOU 2001:48, Swedish Government White Paper, 2001.

Lindgren, Karl-Oskar, Sven Oskarsson, and Christopher Dawes. Can Political Inequalities be Educated Away? Evidence from a Swedish School Reform. American Journal of Political Science, Forthcoming, 2016.

Lundqvist, Heléne. Is It Worth It? On the Returns to Holding Political Office. Working Papers 2013/14, Institut d'Economia de Barcelona (IEB), 2013. 
Merlo, Antonio, Vincenzo Galasso, Massimiliano Landi, and Andrea Mattozzi. The Labor Market of Italian politicians. In Boeri, Tito, Antonio Merlo, and Andrea Prat, editors, The Ruling Class: Management and Politics in Modern Italy. Oxford University Press, Oxford, 2010.

Messner, Matthias and Mattias K. Polborn. Paying Politicians. Journal of Public Economics, 88(12):2423-2445, $2004 . \quad$ URL http://ideas.repec.org/a/eee/pubeco/v88y2004i12p2423-2445.html.

Meyersson, Erik. Islamic Rule and the Empowerment of the Poor and Pious. Econometrica, 82(1):229-269, 2014 URL https://ideas.repec.org/a/wly/emetrp/v82y2014i1p229-269.html.

Myerson, Roger. Incentives to Cultivate Favored Minorities Under Alternative Electoral Systems. American Political Science Review, 87(4):856-869, 1993.

Olson, Mancur. The Logic of Collective Action: Public Goods and the Theory of Groups. Harvard University Press, Cambridge, 1965.

Osborne, Martin and Al Slivinski. A Model of Political Competition with CitizenCandidates. The Quarterly Journal of Economics, 111(1):65-96, 1996. URL http://EconPapers.repec. org/RePEc : oup:qjecon:v:111:y:1996:i:1:p:65-96.

Pande, Rohini. Can Mandated Political Representation Increase Policy Influence for Disadvantaged Minorities? Theory and Evidence from India. American Economic Review, 93(4):1132-1151, 2003. URL https://ideas.repec.org/a/aea/aecrev/v93y2003i4p1132-1151.html.

Persson, Torsten and Guido Tabellini. The Economic Effects of Constitutions. MIT Press, 2003.

Powell, G. Bingham. Elections as Instruments of Democracy - Majoritarian and Proportional Visions. Yale University Press, New Haven, Conn., 2000.

SOU. Ett decennium med personval (Lessons from a Decade of Preference Voting). Swedish Government White Paper: 68, 2007.

Ståhlberg-Carlstedt, Berit and P Sköld. Inskrivningsprov 80 - Testmanual (Enlistment Test 80 - Testing Manual). Report CH 55001-H7, National Defense Research Establishment Report, 1981. 
Statistics Sweden. Åttapartivalet 2010, Allmänna valen Valundersökningen (The eight parties election 2010, general election, electoral study). Official Statistics Sweden Report, 2010.
Sveriges Radio. Would rather be Mayor than Parlia- mentarian (Blir hellre kommunalråd än riksdagsman), 2006. URL http://sverigesradio.se/sida/artikel.aspx? programid=161\&artikel=973385.

Taagepera, Rein and Matthew Shugart. Seats and Votes: The Effects and Determinants of Electoral Systems. Yale University Press, New Haven, Conn., 2000.

Tillmann, Philipp. Entry into Electoral Races and the Quality of Representation. Unpublished, University of Rochester, 2014.

Washington, Ebonya L. Female Socialization: How Daughters Affect Their Legislator Fathers. American Economic Review, 98(1):311-32, 2008. URL https://ideas.repec.org/a/aea/aecrev/v98y2008i1p311-32.html.

Zetterberg, Hans. During Olof Palme's Time - and Afterwords (Under Olof Palmes tid och efteråt), 1988. URL http://zetterberg.org/Press/SvD/sd880229.htm. 
VIII. Figures 

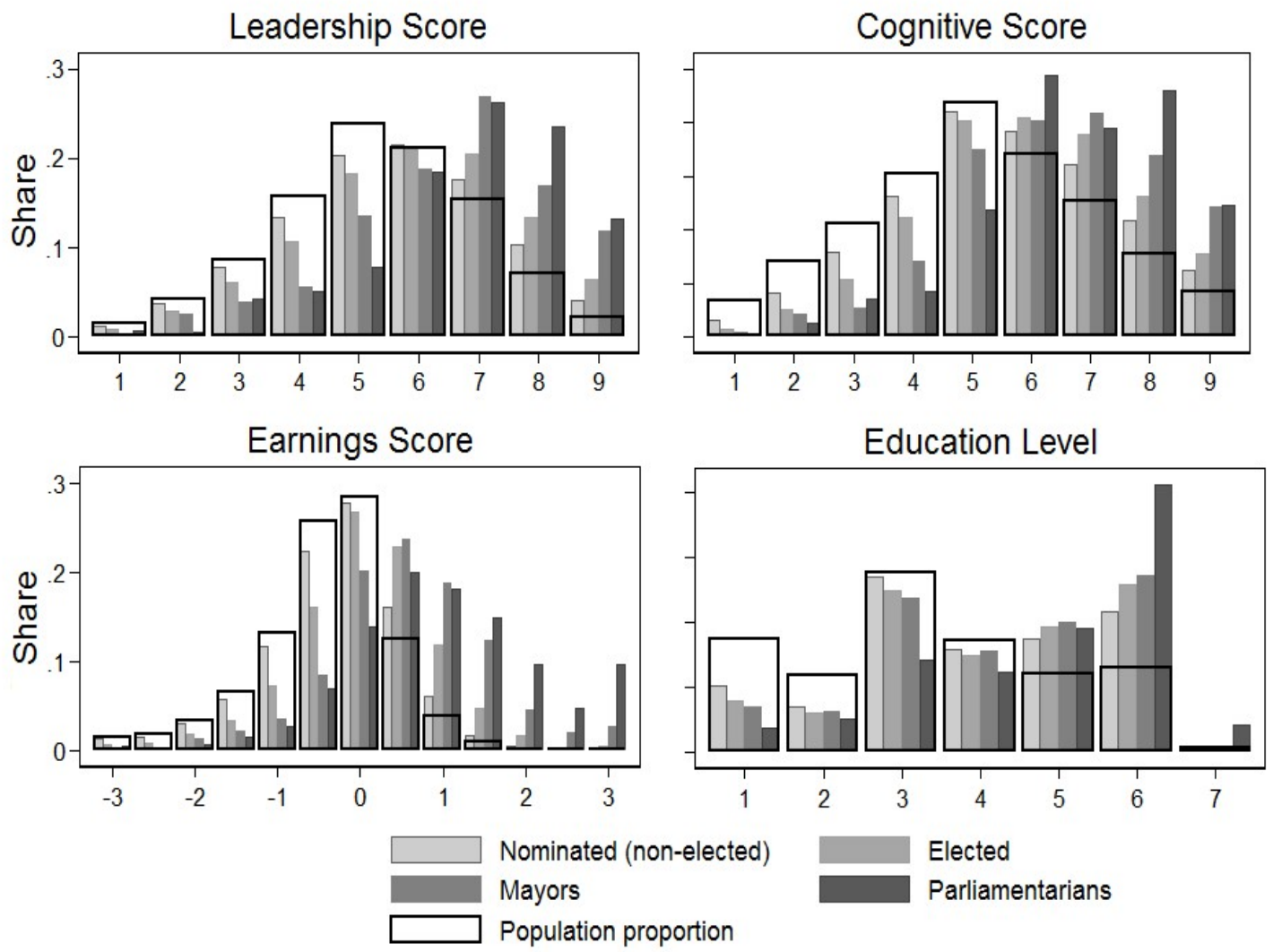

Figure I

Distribution of ability measures in the population and among politicians

Notes: The figure shows comparisons of the distribution of the ability variables among the Swedish working-age population (18 or older) and four categories of politicians: nominated- but non-elected - to a municipal council, elected to a municipal council, mayors, and members of parliament (MPs). The two enlistment scores are shown in the top figures; the bottom left figure shows earnings score, and the bottom right education level. Education level is coded into seven groups based on the formal categorization of Statistics Sweden, namely less than 9 years, 9 years of primary education, 2-year secondary education, 3-year secondary education, tertiary education (less than three years), tertiary education (at least three years) and research degree (licentiate or Ph.D.) All figures are created with pooled individual level data for election years in the 1990s and 2000s (1991, 1994, 1998, 2002, 2006 and 2010). For the cognitive and leadership scores, the sample is restricted to men in the 1951-1980 cohorts. Based on a Kolmogorov-Smirnov test, we can reject that the distributions are the same for each panel and for every pair of categories. 

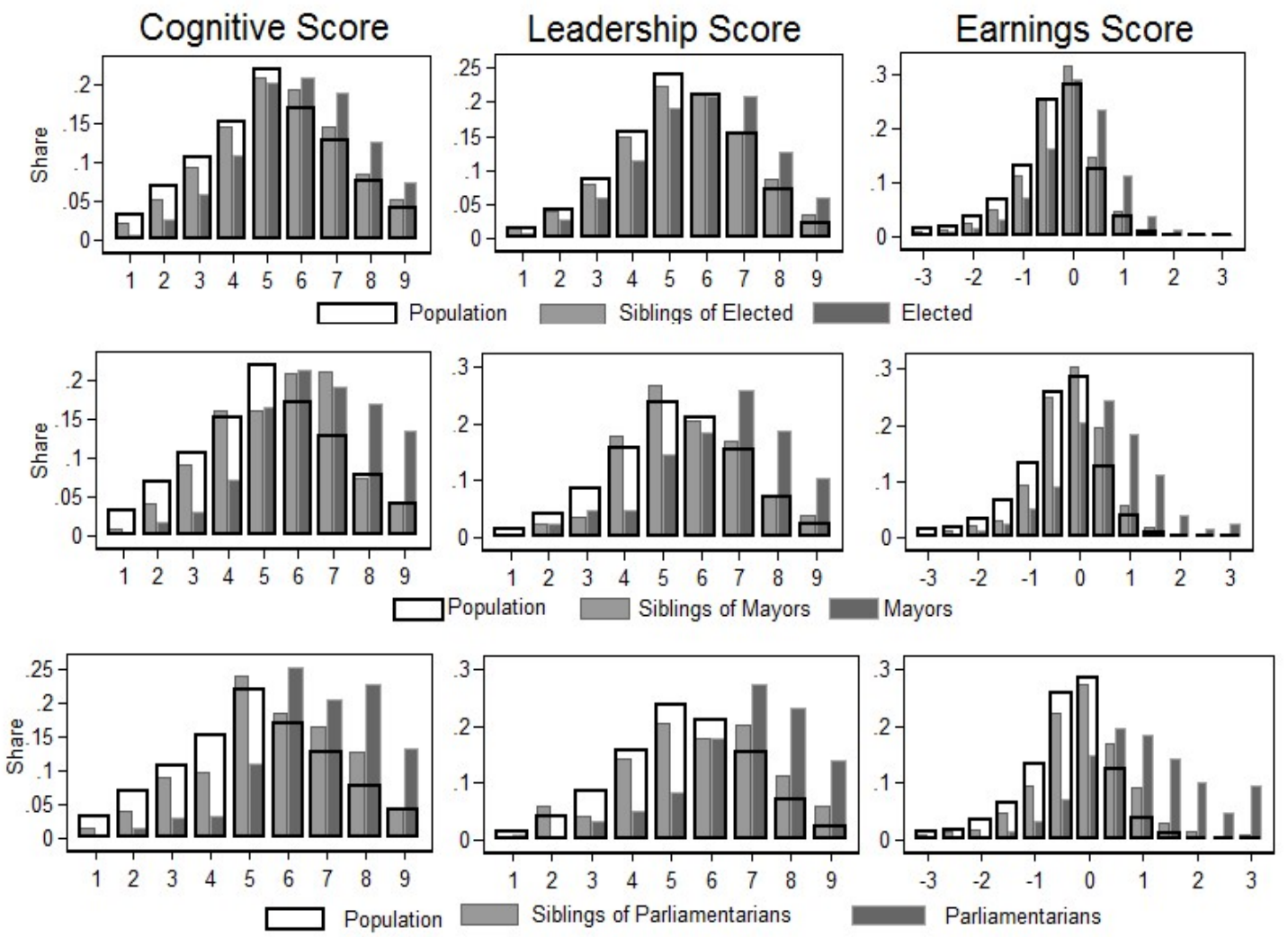

FiguRE II

Distribution of ability measures among elected politicians, their siblings, and the population

Notes: The figure compares the distributions of our ability variables for three categories of politicians (elected to a municipal council, mayors, and members of parliament) and their siblings. The two enlistment scores are shown in the first two columns, the earnings score in the third column. Only politicians with at least one sibling are included. All figures are created with pooled individual level data for election years in the 1990s and 2000s (1991, 1994, 1998, 2002, 2006 and 2010). For the cognitive and leadership scores, the sample is restricted to men in the 1951-1980 cohorts. 


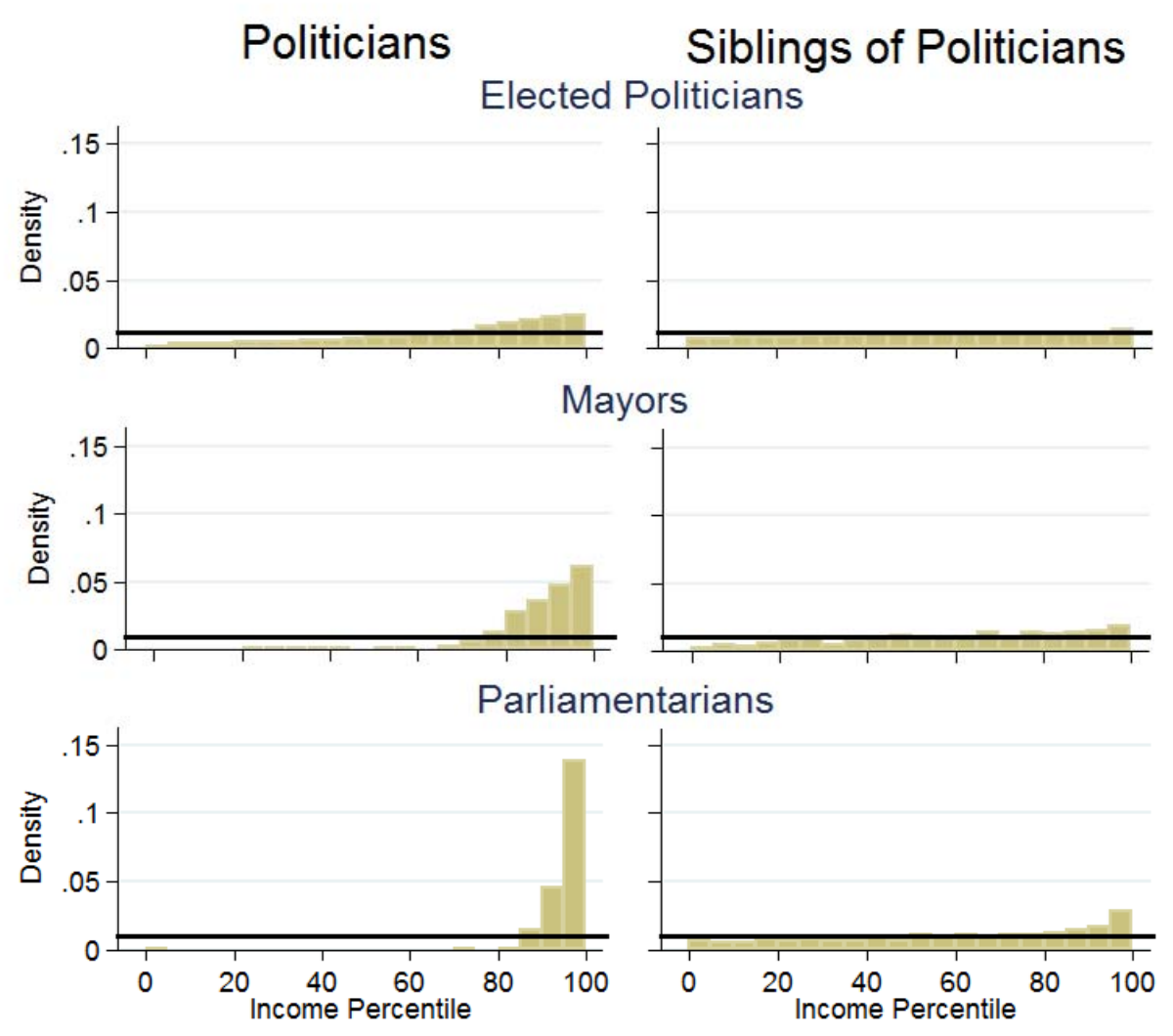

FiguRE III

Distribution of elected politicians and their siblings across the percentiles of population income

Notes: The figure compares the distribution of annual labor incomes of three categories of politicians (elected to a municipal council, mayors, and parliamentarians) to that of their respective siblings. Data from the years 2003, 2007 and 2011 for the adult population (18 or older) was used to compute the percentiles of annual earnings in the population. The proportion of individuals who fall into each 5-percentile bracket is shown in the histograms. The income percentiles are calculated by birth year and gender. Only politicians with at least one sibling are included. 


\section{Fathers 1979}
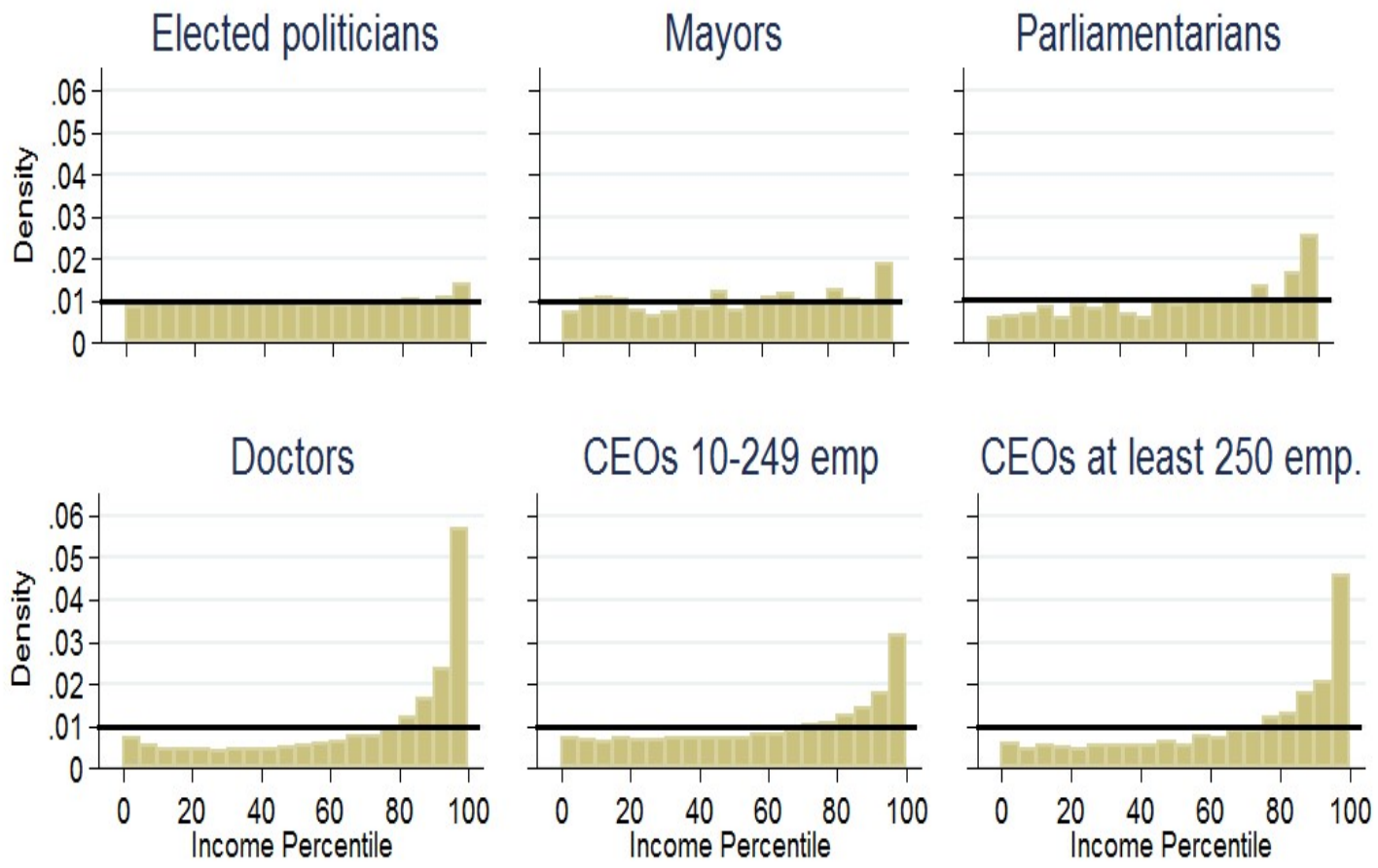

FiguRE IV

Distribution of fathers of politicians and other occupations across the percentiles of population income

Notes: The figure shows the distribution of income among fathers to three types of politicians (elected to a municipal council, mayors, and parliamentarians) and three types of other elite occupations (doctors and CEOs of small or medium, and large enterprises) in 2003, 2007 and 2011. The proportion of fathers who fall into each 5 -percentile bracket is shown in the histograms. The income percentiles are calculated by birth year and gender. Data from year 1979 were used to compute the percentiles of annual earnings for the fathers. Fathers are only included if they are of adult age in year 1979 (18 or older), and politicians are only included if we can find an earnings observation for their father in that year. A father's observation is included as many times as offspring-politicians he produced. 


\section{Elected Politicians Elected Politicians' Fathers, 1979 Social Democrats}
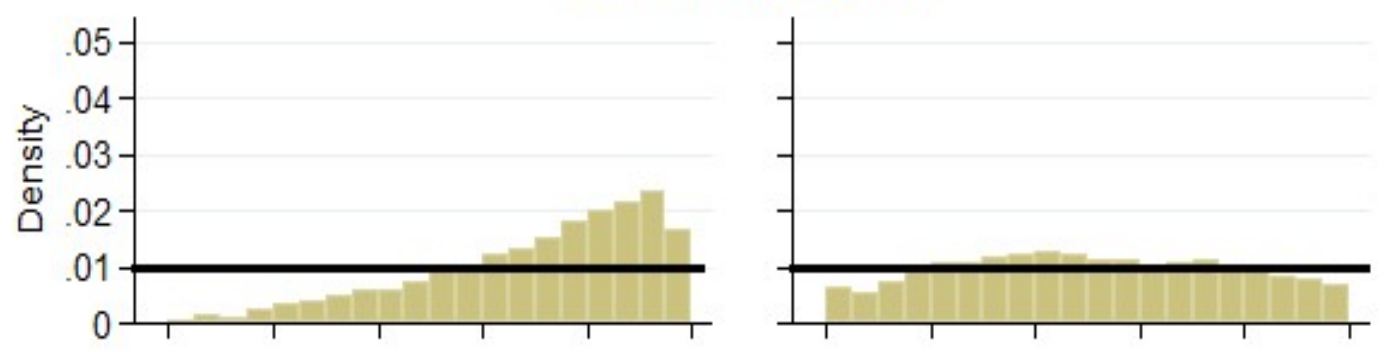

\section{Center Party}
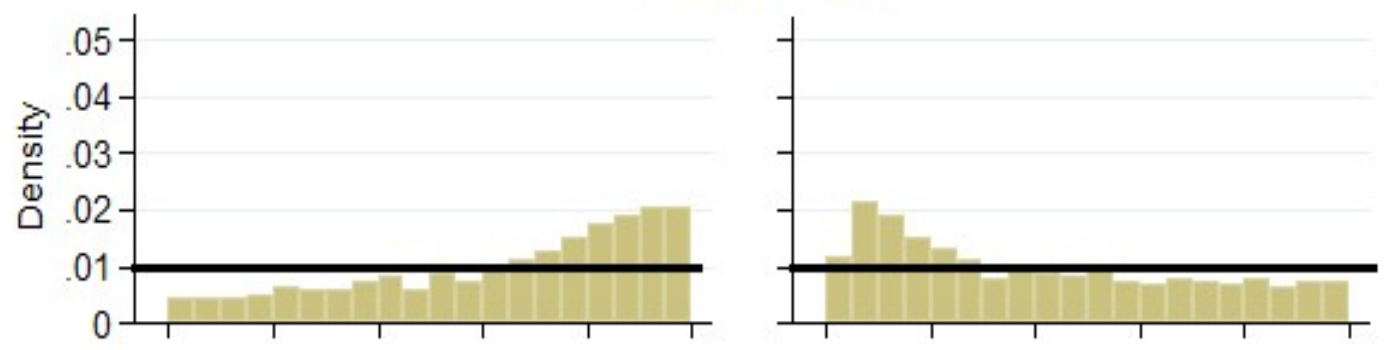

\section{Conservatives}
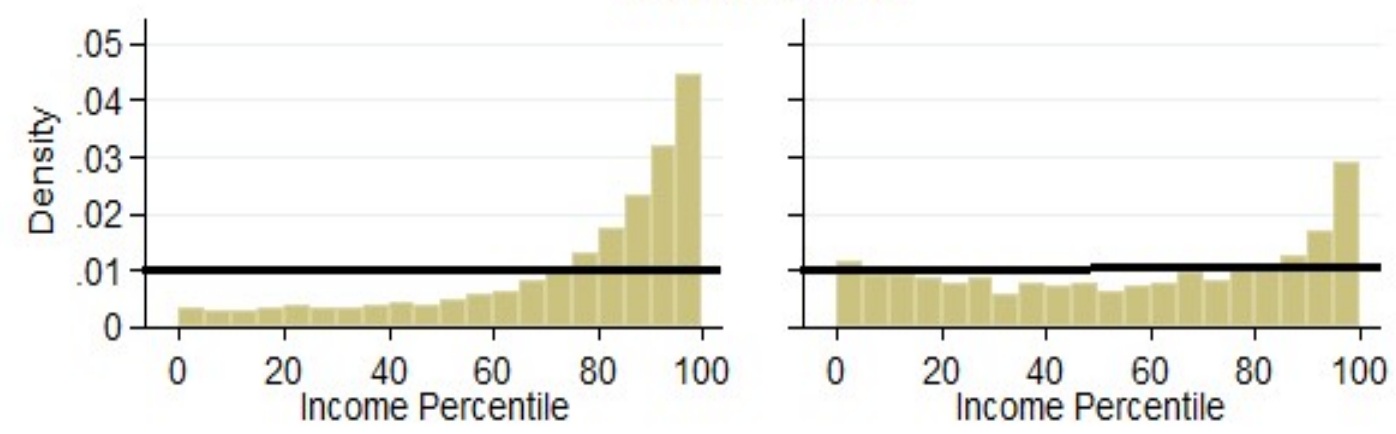

FiguRE V

Distribution of elected politicians and their fathers across the percentiles of population income, by party

Notes: The figure shows distributions of elected politicians (left) and their fathers (right) across the percentiles of the Swedish income distribution. The income percentiles are calculated by birth year and gender. The top (middle/bottom) figure includes politicians elected to a municipal assembly seat for the Social Democrats (Conservative/Center) party. See the notes for Figure 4 for details on the data used. 

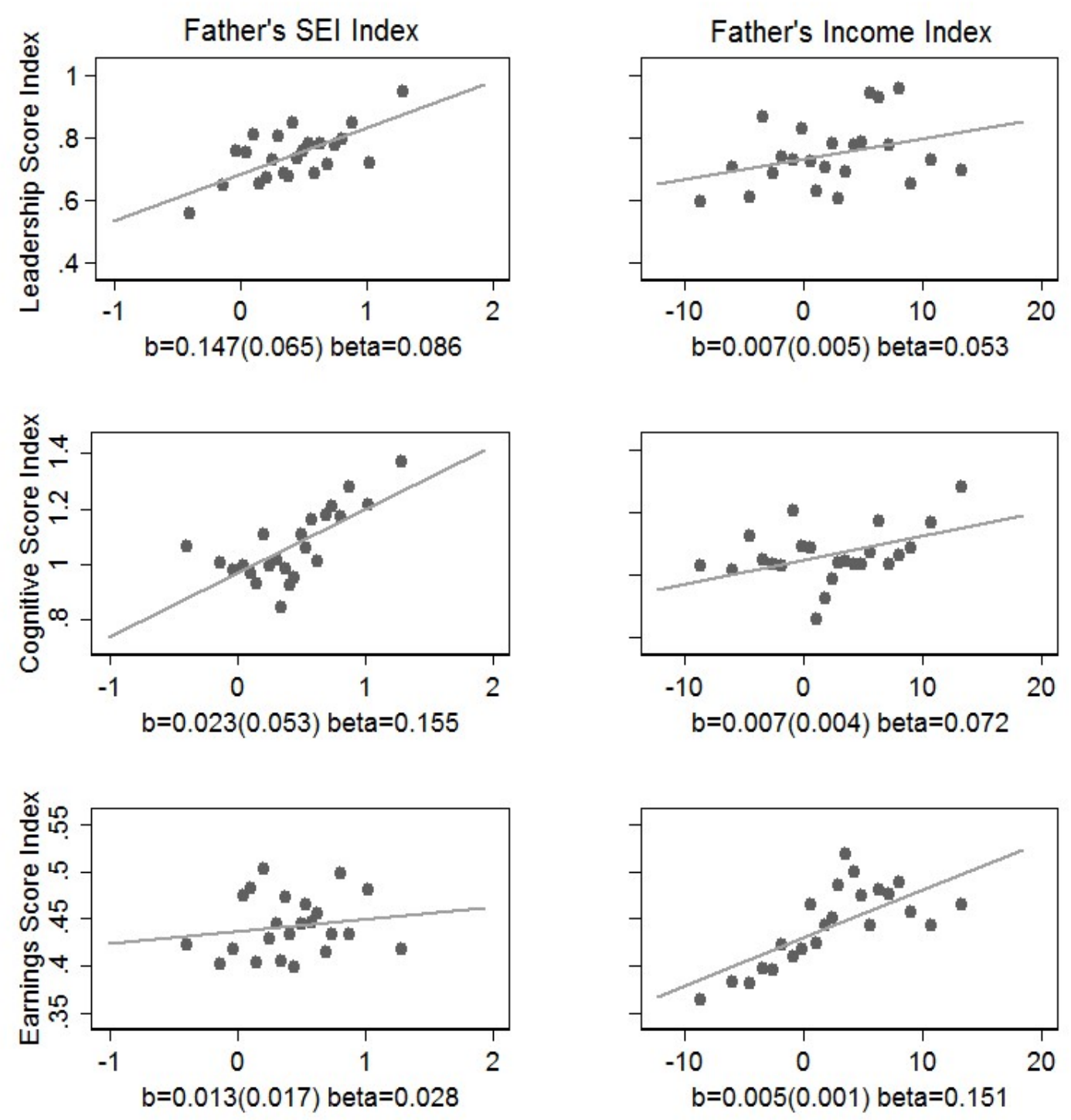

FigURE VI

Correlations between municipal indices of representation and selection

Notes: The figure shows the relationships between competence selection indices (y-axis) and representation indices (x-axis). The representation index is the average among politicians' father minus the average of the fathers of the adult population (18 or older) in the same municipality. Social class of the father in the left column of graphs is measured through father's occupational status, and in the right column through father's income. Father's income is measured by the income percentile in 1979, by birth year. Social class is measured in 1980 and is given the values 1-6 as: (1) Non-skilled manual; (2) Skilled manual; (3) Lower non-manual; (4) Farmer; (5) Intermediary non-manual; and (6) Higher non-manual. The unit of observation ${ }_{3}$ is the municipality and election period. Each dot in the scatter-plots corresponds to the binned average among 50 municipality-election observations. Bins are defined over the support of the $\mathrm{x}$-variable to yield the equal 50 -observation split. The regression line shows the estimated slope coefficient from an OLS regression of the selection index on the representation index. The slope coefficient is displayed below each graph. Standard errors are reported in parentheses, and beta is the normalized relationship in terms of standard errors. The data include all elections from 1998-2010. For the leadership and cognitive scores, data is restricted to men in the 1951-1980 cohorts. 

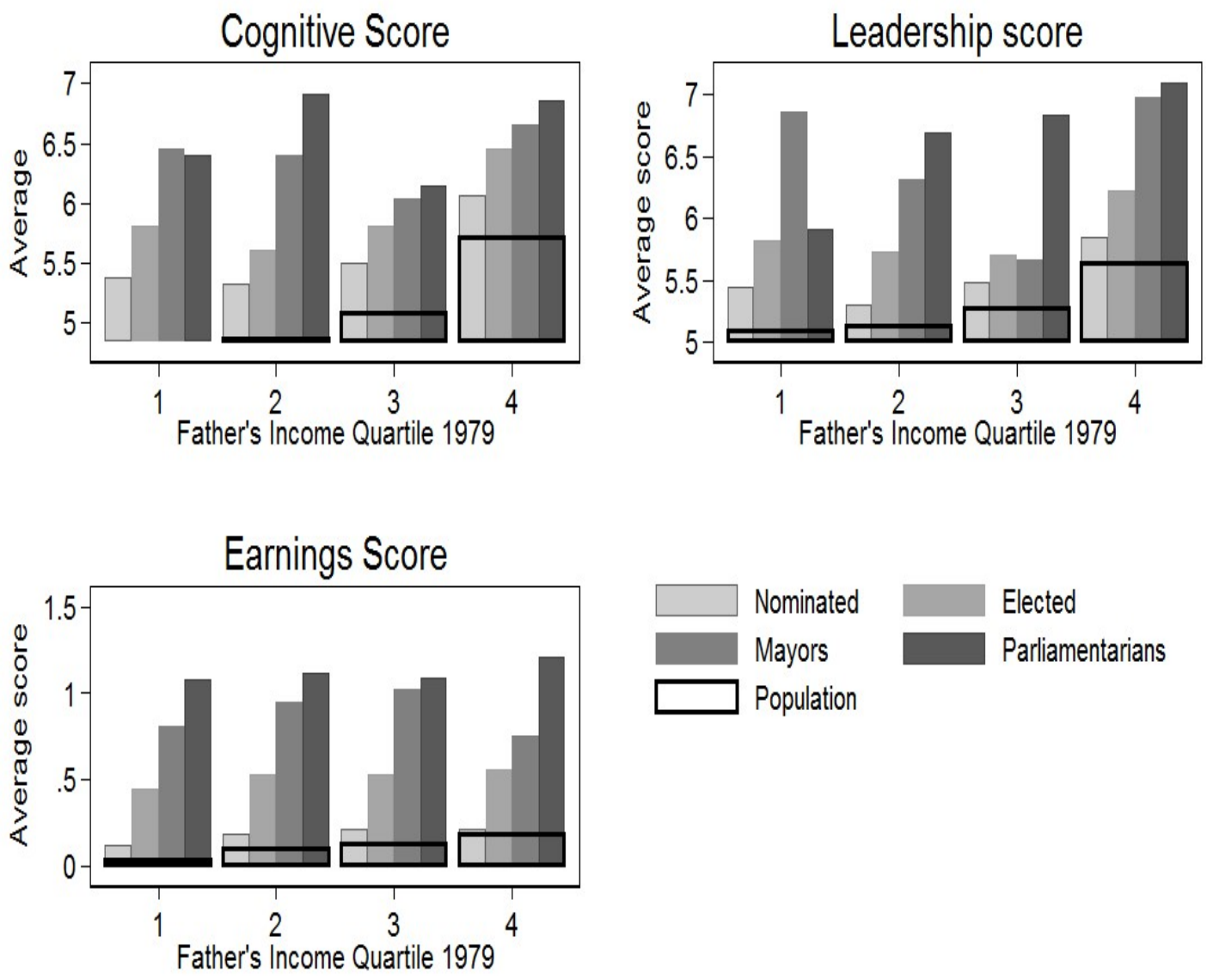

Figure VII

Average ability measures for politicians and general population by father's income quartile

Notes: The figure shows average ability for four types of politicians (nominated - but not elected - to a municipal council, elected to a municipal council, mayors, and parliamentarians) and the working-age population, by income quartile of each individual's father (x-axis), measured in the year 1980. The data are pooled for all politicians elected in the 2000s (2002, 2006 and 2010), and the general population is also sampled in these same years. For the cognitive and leadership scores, the sample is restricted to men in the 1951-1980 cohorts. 


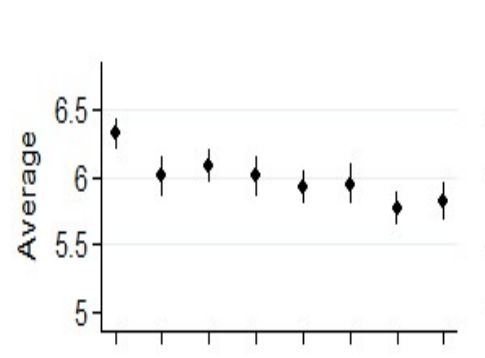

\section{Cognitive Score}
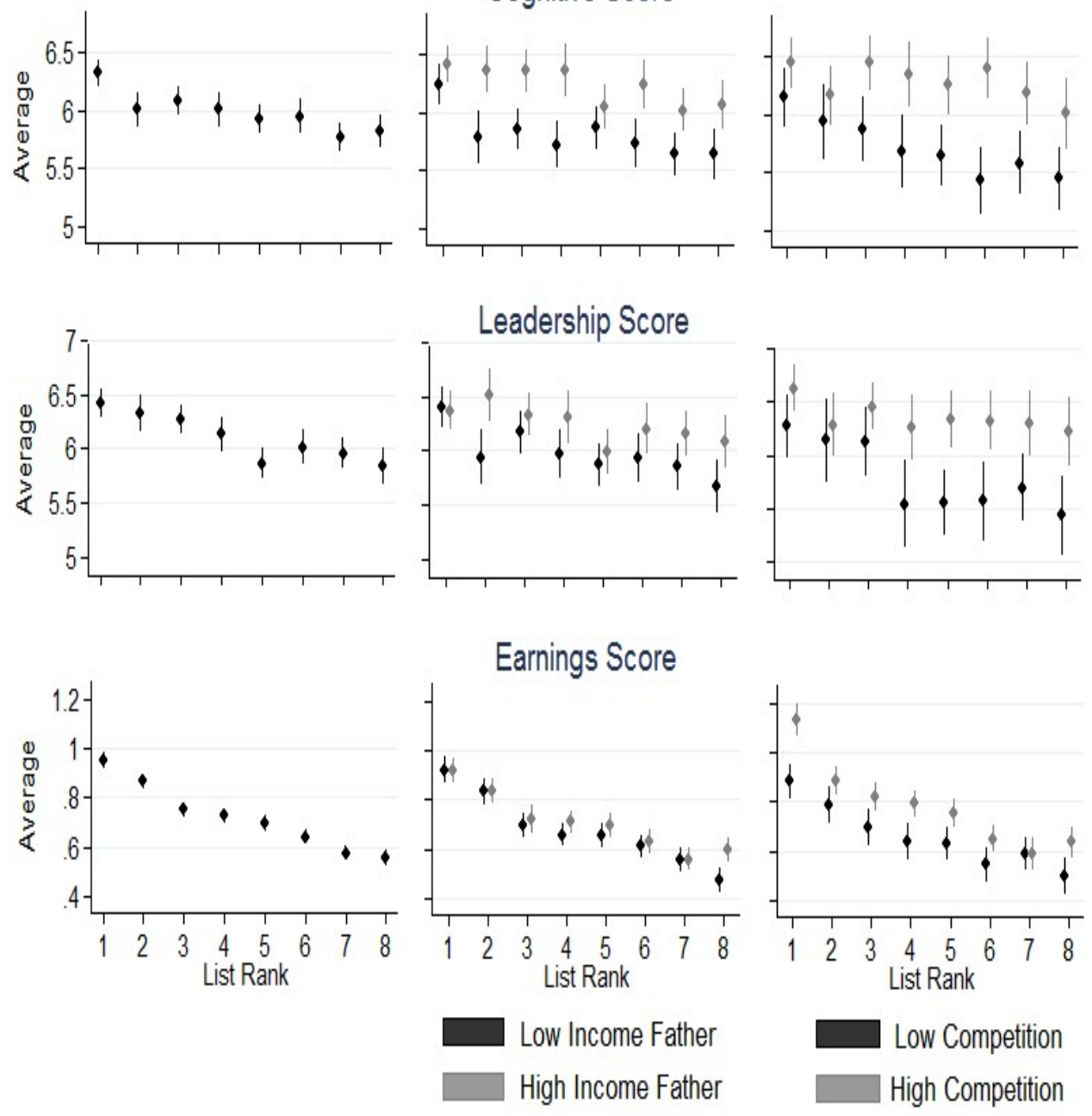

Figure VIII

Average ability by party list rank, divided by parental social background and municipal political competition.

Notes: The figure shows the averages of three ability variables by ballot rank. The top (middle/bottom) graph shows the means for leadership score (cognitive score/residual earnings measure). The data come from elections held during 1991-2010 (1991, 1994, 1998, 2002, 2006 and 2010). In the left column of plots, the black dots show the mean of the competence variable for the politicians in each ballot rank, and the vertical lines running through each dot denote $95 \%$ confidence intervals. In the middle column of plots, similar means and confidence intervals are shown, but the politician observations are split by whether their fathers have incomes below or above the median father in the population. The black dots show the summary statistics for the politicians with low-income fathers, and the gray dots show the statistics for the politicians with high-income fathers. In the right column of plots, similar mes 3 s and confidence intervals are reported for two groups of municipality-election observations, split by the median of political competition. Political competition is computed as the win margin of the majority bloc of parties, left or center-right. The black dots show the summary statistics for the politicians in low-competition contexts, and the gray dots show the statistics for the politicians in high-competition contexts. For the cognitive and leadership scores, the sample is restricted to men in the 1951-1980 cohorts. 


\section{TABLES}

TABLE I

SUMMARY STATISTICS FOR THE POPULATION AND POLITICIANS

\begin{tabular}{|c|c|c|c|c|c|c|}
\hline & \multicolumn{2}{|c|}{ Population } & \multicolumn{4}{|c|}{ Politicians } \\
\hline & Mean & Std. Dev. & Nominated & Elected & Mayors & MPs \\
\hline Women & 51.0 & 50.0 & 39.9 & 40.8 & 24.9 & 42.2 \\
\hline Age & 48.4 & 18.9 & 50.3 & 50.8 & 52.5 & 49.6 \\
\hline Foreign born (\%) & 13.7 & 34.4 & 7.4 & 5.8 & 2.6 & 4.1 \\
\hline Leadership score (1-9) & 5.3 & 1.7 & 5.6 & 5.9 & 6.5 & 6.8 \\
\hline Cognitive score (1-9) & 5.1 & 1.9 & 5.6 & 6.0 & 6.4 & 6.7 \\
\hline Years of education & 11.7 & 3.0 & 12.8 & 13.1 & 13.2 & 14.5 \\
\hline Earnings score (z-score) & 0.05 & 0.94 & 0.18 & 0.55 & 0.97 & 1.33 \\
\hline Observations $(*)$ & $42,096,789$ & & 236,950 & 79,463 & 1,569 & 2,086 \\
\hline
\end{tabular}

Notes: This table reports descriptive statistics on social attributes and on the various measures of competence. These statistics were computed for the Swedish working-age population (18 or older), and for politicians, pooling individual level data for election years in the 1990s and 2000s (1991, 1994, 1998, 2002, 2006 and 2010). Politicians are divided into four hierarchical categories: nominated (but not elected) for a municipal assembly seat, elected for a municipal assembly seat, mayor, and member of (national) parliament. (*) Observations reports the highest number of individual observations used in the column. For the enlistment measures of ability, only male politicians in the 1951-1980 cohorts are included, which gives a smaller number of observations for these measures. A politician is included once for each election period in which he/she serves, so the Observations number is larger than the number of unique individuals. 
TABLE II

AbiLity By SELECTED ELITE ocCupations

\begin{tabular}{lcccccc}
\hline & $\begin{array}{c}\text { Leadership } \\
\text { score }\end{array}$ & $\begin{array}{c}\text { Cognitive } \\
\text { score }\end{array}$ & $\begin{array}{c}\text { Earnings } \\
\text { score }\end{array}$ & $\begin{array}{c}\text { Years of } \\
\text { schooling }\end{array}$ & $\begin{array}{c}\text { Labor } \\
\text { earnings }\end{array}$ & Obs \\
\hline Nominated to mun. council & 5.5 & 5.5 & 0.07 & 13.6 & 286.2 & 24535 \\
Municipal councilors & 5.8 & 5.9 & 0.38 & 13.8 & 379.0 & 8870 \\
Mayors & 6.4 & 6.2 & 0.79 & 13.9 & 679.4 & 247 \\
Parliamentarians & 6.6 & 6.4 & 0.98 & 14.8 & 802.2 & $320\left(^{*}\right)$ \\
CEOs (10 - 24 employees) & 6.1 & 5.8 & 0.81 & 13.6 & 675.6 & 6825 \\
CEOs (25 - 249 employees) & 6.4 & 6.2 & 1.12 & 14.2 & 1046.2 & 6885 \\
CEOs ( $\geq 250$ employees) & 6.8 & 6.7 & 1.29 & 15.4 & 1926.0 & 1470 \\
Medical Doctors & 6.5 & 7.4 & 1.13 & 17.1 & 640.0 & 29514 \\
Lawyers and Judges & 6.5 & 6.8 & 0.69 & 17.0 & 568.0 & 5308 \\
Economists & 5.9 & 7.0 & 0.38 & 20.4 & 530 & 248 \\
Political Scientists & 5.8 & 6.8 & 0.61 & 20.4 & 513.3 & 306 \\
\hline
\end{tabular}

Notes: The table shows ability averages among politicians (nominated but not elected in row 1, elected municipal councilors in row 2, mayors in row 3, and parliamentarians in row 4) and among individuals in seven occupational categories, which make up other "elite" occupations in Swedish society. Columns 1 and 2 report the means for the two enlistment scores, the leadership score and the cognitive score (measured on a 1-9 scale). Column 3 reports the means of our earnings score, and column 4 reports average years of education. Column 5 reports the mean of annual labor earnings (in 1000s Swedish Kronor; 1 SEK 0.8USD), and finally, column 6 reports the number of individuals classified into each elite occupation. The data are from 2011 and includes the full Swedish working-age population (18-65). Individuals working in universities are identified based on a 5-digit industry code that indicates employment at a university. For the cognitive score and the leadership score, data is restricted to men in the 19511980 cohorts. $\left(^{*}\right)$ Removing individuals older than 65 reduces the number of parliamentarians below the full size of parliament. 


\section{Online Appendix to "Who Becomes a Politician?": Supplementary Analysis, Figures and Tables}

This Online Appendix includes additional figures in Section A and additional tables in Section B. Section C offers an analysis of self-selection decisions and party screening, by first laying out a formal model and then taking its predictions to the data. 


\section{A Figures}
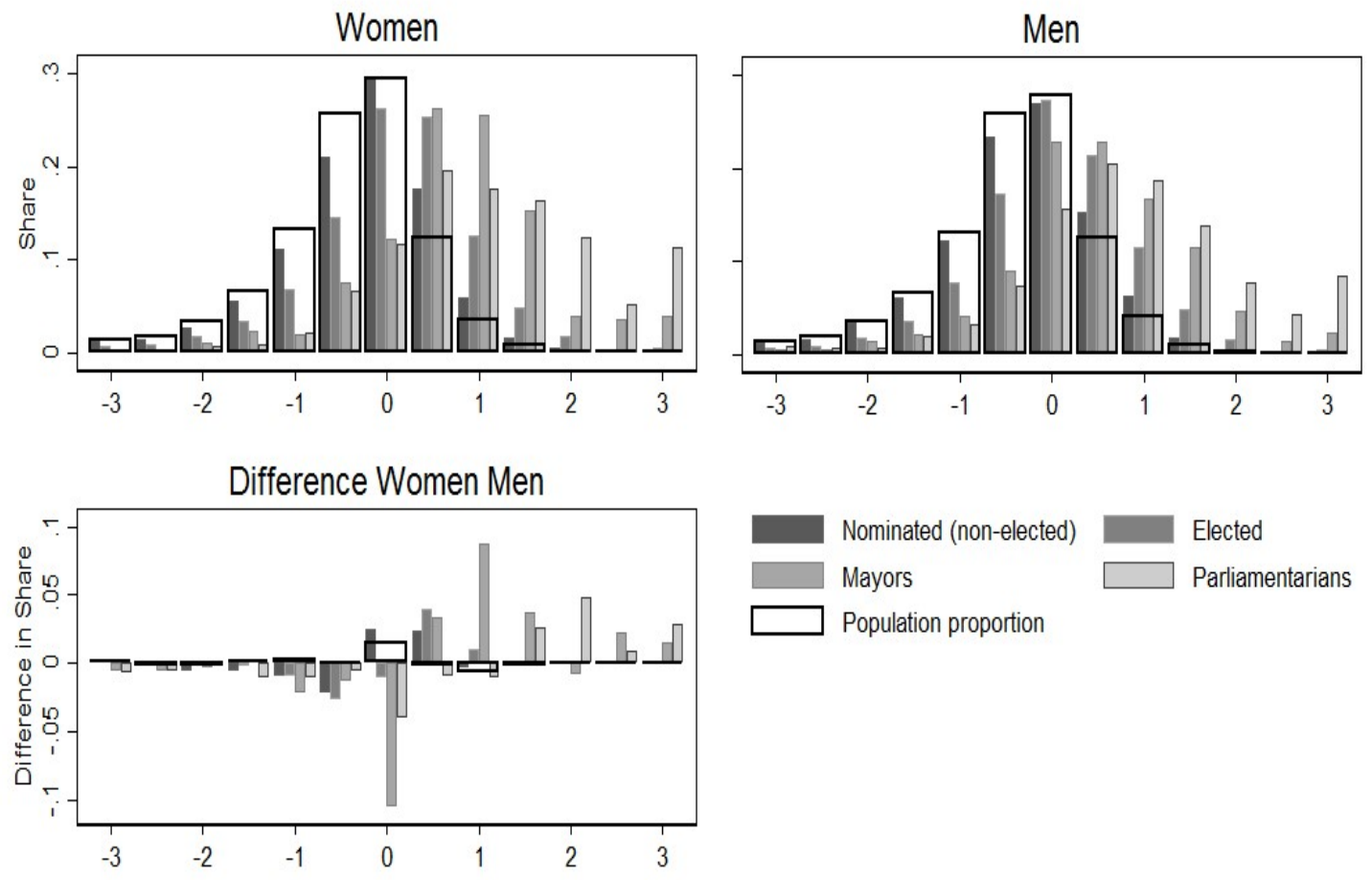

Figure A.1

Distribution of earnings score in the population and among politicians, by gender

Notes: The figure shows comparisons of the distribution of the earnings score among the Swedish working-age population (18-72) and four categories of politicians: nominated (but non-elected) to a municipal council, elected to a municipal council, mayors, and members of parliament, by gender. The figures are created with pooled individual level data for election years in the 1990s and 2000s (1991, 1994, 1998, 2002, 2006 and 2010). 

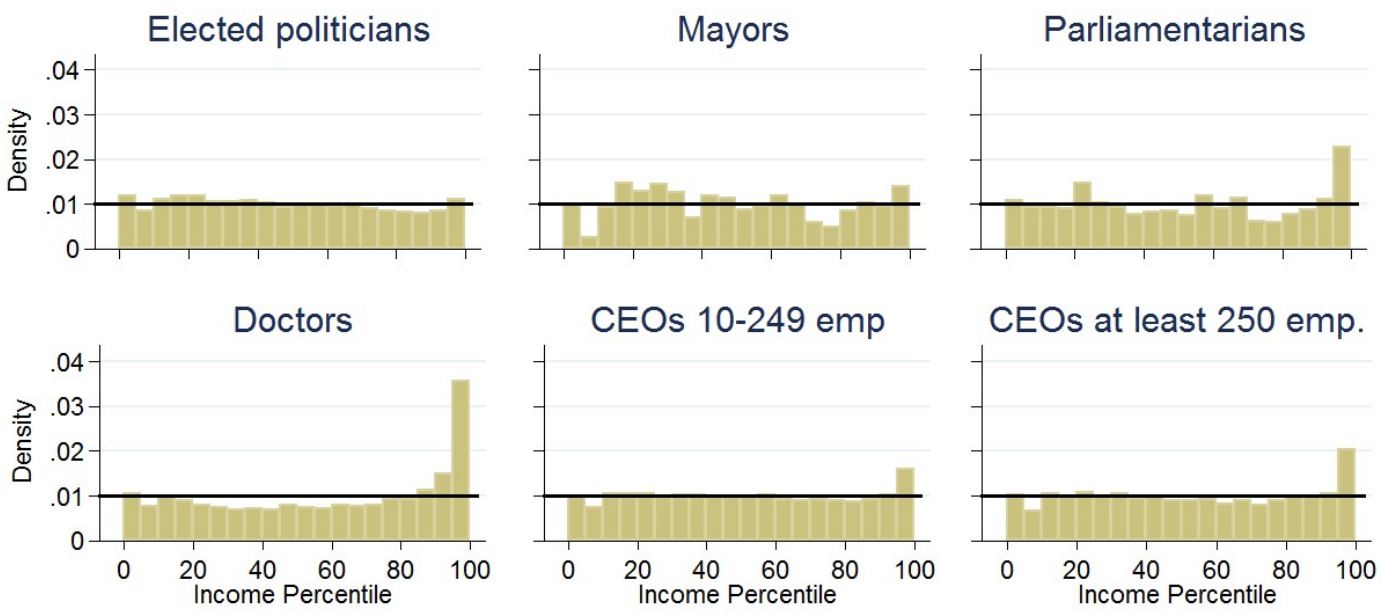

FiguRe A.2

Distribution across the percentiles of population income of mothers of elected politicians, mayors, parliamentarians, doctors and CEOs

Notes: The figure shows the distribution of income among mothers to three types of politicians (elected to a municipal council, mayors, and parliamentarians) and three types of other elite occupations (doctors and CEOs of small or medium, and large enterprises) in 2003, 2007 and 2011. The proportion of individuals who fall into each 5-percentile bracket is shown in the histograms. The income percentiles are calculated by birth year and gender. Data from year 1979 were used to compute the percentiles of annual earnings for the mothers. Mothers are only included if they are of adult age in year 1979 (18-or older), and politicians are only included if we can find an earnings observation for their mother in that year. 


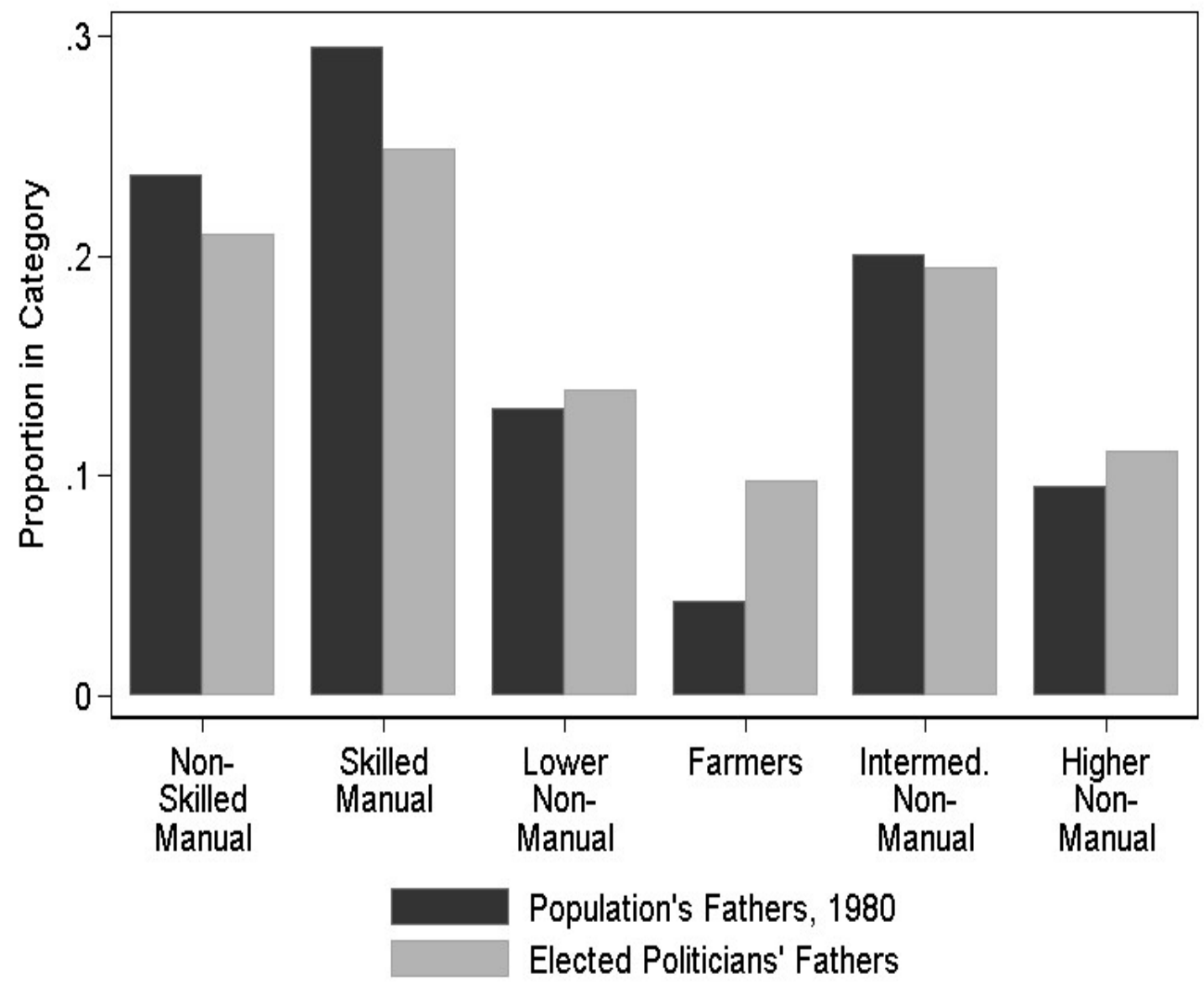

Figure A.3

Distribution of 2010 politicians' parental social class, measured in 1980 and compared to the 2010 populations social class.

Notes: The figure shows the distributions across six social classes of politicians elected to municipal council (light gray bars) and their parents (dark gray bars). The height of the bars show the proportion of individuals in each social class. Elected politicians are measured in year 2010. Parents' social class is measured in 1980. Only politicians for whom we can identify a father or a mother with a non-missing social class are included. In cases where we can identify the social class of both parents, only the one with the highest social class is included in the figure. 

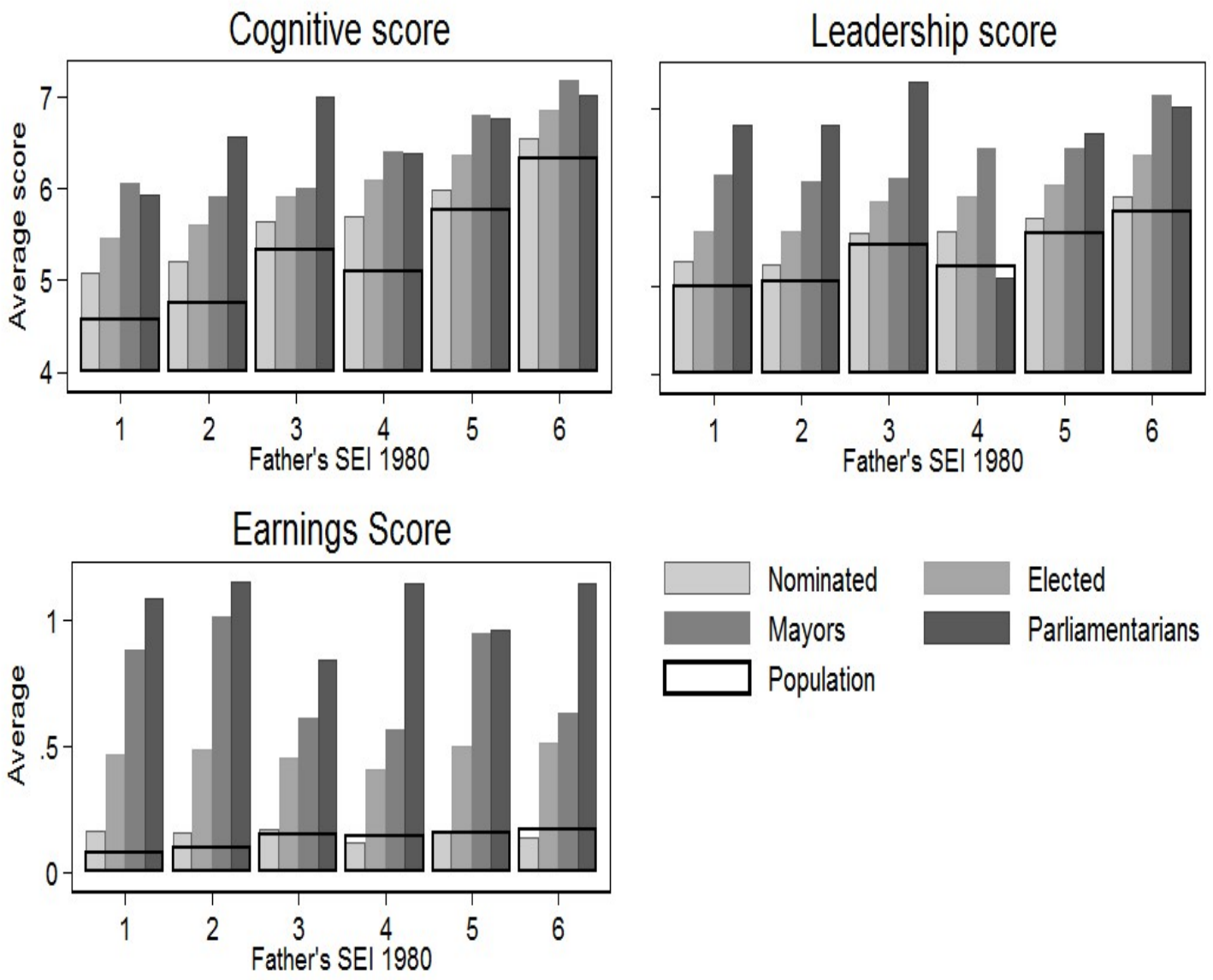

Figure A.4

Distribution of 2010 politician parental social class, measured in 1980 and compared to the 2010 population parental social class.

Notes: The figure shows the distributions across six social classes of parents of four categories of politicians (running in 2010, solid bars) and parents of individuals in the general population (transparent bars). The height of the bars shows the proportion of parents in each occupational social class. Parents' social class is measured in 1980. Only politicians for whom we can identify a father or a mother with a non-missing social class are included. In cases where we can identify the social class of both parents, only the one with the highest social class is included in the figure. The class division corresponds closely to the EGP social-class scheme (Erikson and Goldthorpe 1992). We define six classes as: (1) non-skilled manual workers, (2) skilled manual workers, (3) lower non-manual workers, (4) farmers, (5) intermediate non-manual workers, and (6) higher non-manual workers. 

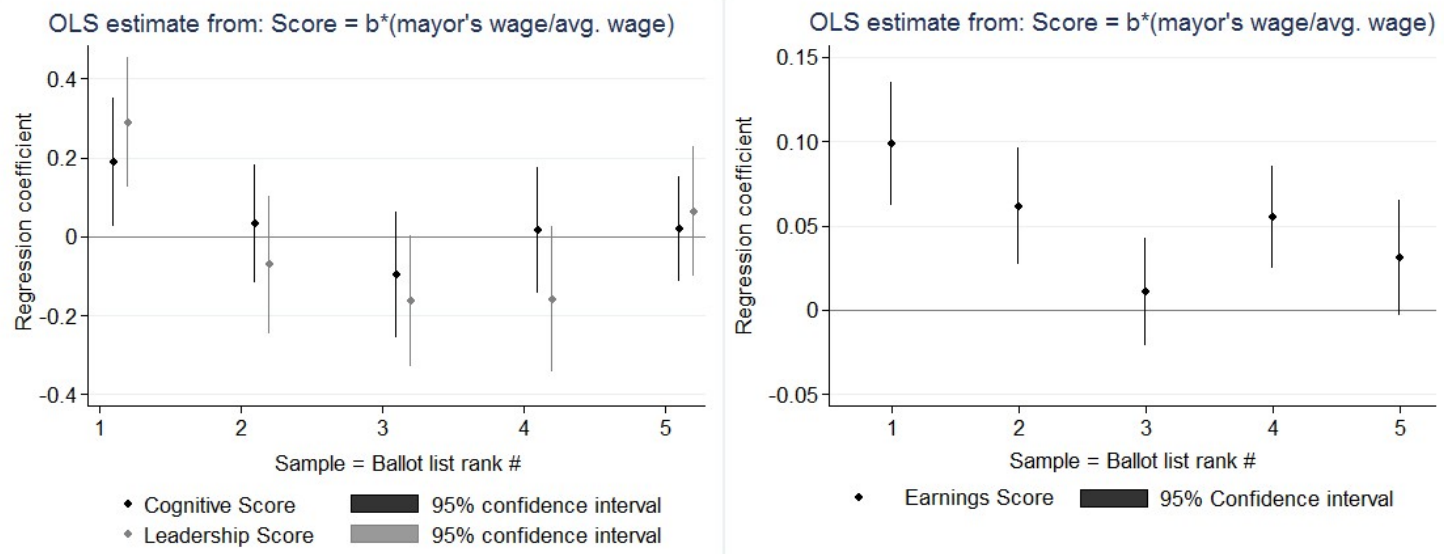

FiguRE A.5

Estimated bivariate relationships between politician ability and the mayor's wage relative to the municipal population, by electoral ballot rank

Notes: The figure shows estimation results for the relationship between politician ability and the mayor's annual earnings as a fraction of the average annual earnings in the municipality that he or she governs. Bivariate OLS regressions are run in sub-samples based on electoral ballot rank. These sub-samples are denoted on the x-axis. In the left graph, the cognitive score (black color) and the leadership score (gray color) are each used as the dependent variable. In the right graph, the dependent variable is the earnings score measure. The dots represent the size of the point estimates and the vertical lines $95 \%$ confidence intervals. Data is extracted for the election years in the 1990s and 2000s (1991, 1994, 1998, 2002, 2006, and 2010). For the enlistment scores, we only use data for men in the 1951-1980 cohorts. 

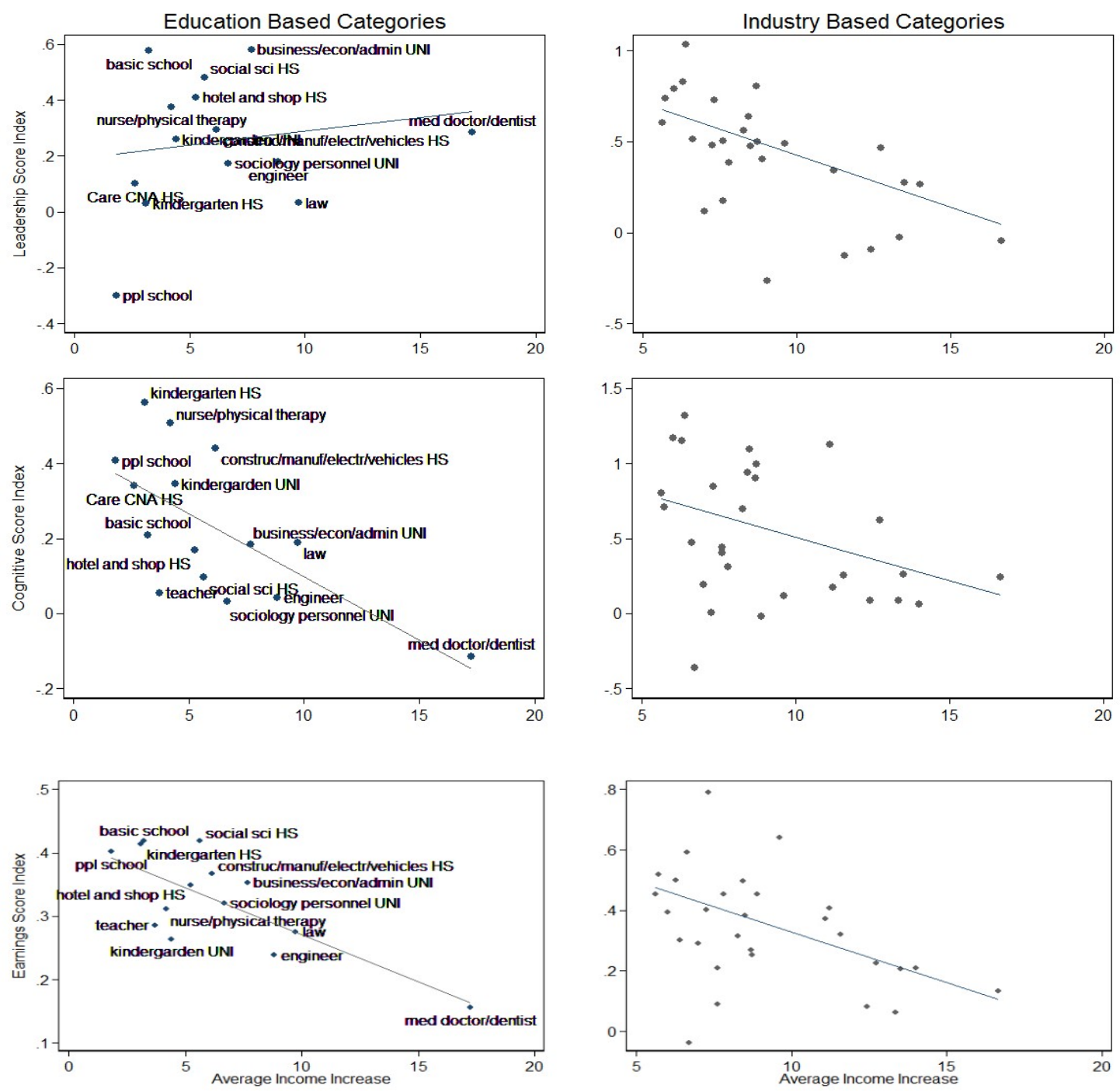

FiguRE A.6

Selection by ability and politician sector of work

Notes: The figure shows the relationship between the ability selection indices and the age-earnings profile of various occupation types. The x-axis of the plots in the left (right) column shows the average increase in annual earnings, in 1000 SEK, by education orientation (industry sector) dividing individuals in two groups, with and without tertiary education-, while the y-axis shows the selection indices by education (sector). Each selection index is computed as mean ability among the elected municipal politicians for each occupation minus mean ability among non-politicians in the same occupation in the working-age population (18-72). Average earnings increases are computed from annual individual-level data for the Swedish working-age population (1990-2012). Individuals with the same occupation are divided into age brackets of five years and year-on-year average earnings hikes are computed for the entire peried as earnings $(\mathrm{t}+1)$-earnings $(\mathrm{t})$. The regression lines are estimated by OLS. The cognitive and leadership scores are restricted to 1951-1980 cohort men. 


\section{B TABLES}

TABLE B.1

CORRESPONDENCE BETWEEN THE SUB-TRAITS OF THE LEADERSHIP SCORE AND THE Big 5 PERSONALITY TRAITS

\begin{tabular}{|c|c|c|}
\hline Sub-trait & Details of component & $\begin{array}{l}\text { Corresponding } \\
\text { Big } 5 \text { trait }\end{array}$ \\
\hline \multirow{4}{*}{ Social Maturity } & Extraversion & Extraversion \\
\hline & Having friends & Extraversion \\
\hline & Taking responsibility & Conscientiousness \\
\hline & Independence & Openness \\
\hline \multirow{3}{*}{ Psychological Energy } & Perseverance & Conscientiousness \\
\hline & Ability to fulfill plans & Conscientiousness \\
\hline & Ability to remain focused & Conscientiousness \\
\hline \multirow{2}{*}{ Intensity } & $\begin{array}{l}\text { Capacity to generate initiative } \\
\text { without external pressure }\end{array}$ & Conscientiousness \\
\hline & $\begin{array}{l}\text { Intensity and frequency } \\
\text { of free time activities }\end{array}$ & Openness \\
\hline \multirow{3}{*}{ Emotional Stability } & Disposition to Anxiety & Neuroticism \\
\hline & Ability to control and channel nervousness & Neuroticism \\
\hline & Tolerance of stress & Neuroticism \\
\hline $\begin{array}{l}\text { Notes: The Swedish enlistm } \\
\text { ership Score." The manual } \\
\text { first scores the conscript on } \\
\text { a final score. The sub-traits } \\
\text { column 3, these personality } \\
\text { Nilsson (2014)). }\end{array}$ & $\begin{array}{l}\text { orocedure assesses conscripts' psychological traits and } \\
\text { owed by the trained psychologist to make this assessm } \\
\text { sub-traits, listed in column } 1 \text { of the table, and then m } \\
\text { ture certain aspects of the conscript's personality, whi }\end{array}$ & $\begin{array}{l}\text { nbines them into a "Lead } \\
\text { at specifies a process tha } \\
\text { ges these assessments int } \\
\text { are listed in column } 2 \text {. In }\end{array}$ \\
\hline
\end{tabular}


TABLE B.2

Correlations Between ability measures, 2011

\begin{tabular}{lccc}
\hline & Leadership score & Cognitive score & Years of education \\
\hline Leadership score & 1 & & \\
Cognitive score & 0.338 & 1 & \\
Years of education & 0.300 & 0.511 & 1 \\
Earnings Score & 0.201 & 0.167 & 0.076 \\
\hline
\end{tabular}

Notes: This table reports bivariate correlation coefficients between the various measures of ability. The underlying data encompass the Swedish working age population (18-72) in 2011. For the cognitive and leadership scores, the sample is restricted to men in the 1951-1980 cohorts. 
TABLE B.3

SUMmaRY STATISTICS FOR THE POPULATION AND POLITICIANS WITH ADDITIONAL VARIABLES

\begin{tabular}{|c|c|c|c|c|c|c|}
\hline & \multicolumn{2}{|c|}{ Population } & \multicolumn{4}{|c|}{ Politicians } \\
\hline & Mean & Std. Dev. & Nominated & Elected & Mayors & MPs \\
\hline Women & 51 & 50 & 39.9 & 40.8 & 24.9 & 42.2 \\
\hline Age & 48.4 & 18.9 & 50.3 & 50.8 & 52.5 & 49.6 \\
\hline Foreign born $(\%)$ & 13.7 & 34.4 & 7.4 & 5.8 & 2.6 & 4.1 \\
\hline Leadership score (1-9) & 5.3 & 1.7 & 5.6 & 5.9 & 6.5 & 6.8 \\
\hline Cognitive score (1-9) & 5.1 & 1.9 & 5.6 & 6 & 6.4 & 6.7 \\
\hline Years of education & 11.7 & 3 & 12.8 & 13.1 & 13.2 & 14.5 \\
\hline Earnings Score (z-score) & 0.05 & 0.94 & 0.18 & 0.55 & 0.97 & 1.33 \\
\hline Fathers inc perc. (1979) & 51.7 & 28.9 & 49.6 & 51.3 & 51.7 & 59.9 \\
\hline Mothers inc perc. (1979) & 46.9 & 28.5 & 45.9 & 47.2 & 47.2 & 50.8 \\
\hline Fathers SEI =1 (1980) & 0.23 & 0.42 & 0.2 & 0.2 & 0.17 & 0.13 \\
\hline Fathers SEI =2 (1980) & 0.28 & 0.45 & 0.23 & 0.23 & 0.19 & 0.18 \\
\hline Fathers SEI $=3(1980)$ & 0.14 & 0.34 & 0.13 & 0.14 & 0.15 & 0.15 \\
\hline Fathers SEI $=4(1980)$ & 0.05 & 0.21 & 0.13 & 0.12 & 0.16 & 0.07 \\
\hline Fathers SEI $=5(1980)$ & 0.21 & 0.41 & 0.19 & 0.19 & 0.21 & 0.23 \\
\hline Fathers SEI $=6(1980)$ & 0.1 & 0.3 & 0.11 & 0.11 & 0.12 & 0.24 \\
\hline Observations & $42,096,789$ & & 236,950 & 79,463 & 1,569 & 2,086 \\
\hline
\end{tabular}

Notes: This table reports descriptive statistics on social attributes and on the various measures of competence. These statistics were computed for the Swedish working-age population (18 or older), and for politicians, pooling individual level data for election years in the 1990s and 2000s (1991, 1994, 1998, 2002, 2006 and 2010). A politician is included once for each election period in which he/she serves. For the cognitive and leadership scores, the sample is restricted to men in the 1951-1980 cohorts. Politicians are divided into four hierarchical categories: nominated (but not elected) to municipal council, elected to municipal council, mayor, and member of (national) parliament.(*) Observations reports the highest number of individual observations used in the column. For the enlistment measures of ability, only male politicians in the 1951-1980 cohorts are included, which gives a smaller number of observations for these measures. A politician is included once for each election period in which he/she serves, so the Observations number is larger than the number of unique individuals. 
TABLE B. 4

AVERAGE ABILITY SELECTION INDICES OF ELECTED POLITICIANS AND TOP-RANKED POLITICIANS ON LOCAL PARTIES' ELECTORAL BALLOTS, BY PARTY-INTERNAL CAREER PROSPECTS

\begin{tabular}{|c|c|c|c|c|c|c|c|c|}
\hline & \multicolumn{8}{|c|}{ Probability that the politician's party appoints the mayor } \\
\hline & \multicolumn{2}{|c|}{$0 \%$} & \multicolumn{2}{|c|}{$1-50 \%$} & \multicolumn{2}{|c|}{$51-99 \%$} & \multicolumn{2}{|c|}{$100 \%$} \\
\hline & Elected & Top & Elected & Top & Elected & Top & Elected & Top \\
\hline Leadership Score & 0.75 & 0.95 & 0.94 & 1.25 & 0.79 & 1.11 & 0.65 & 1.52 \\
\hline Cognitive Score & 1.29 & 1.42 & 1.15 & 1.37 & 1.03 & 1.41 & 0.90 & 1.92 \\
\hline Earnings Score & 0.35 & 0.51 & 0.51 & 0.79 & 0.58 & 0.88 & 0.60 & 1.13 \\
\hline Observations $(*)$ & \multicolumn{2}{|c|}{5,394} & \multicolumn{2}{|c|}{1,584} & \multicolumn{2}{|c|}{1,032} & \multicolumn{2}{|l|}{456} \\
\hline
\end{tabular}

Notes: The table shows the means of three ability variables by the probability that the politician's party appoints the mayor in his/her municipality. We measure this probability for each municipality as the proportion of election periods that a party was responsible for appointing the mayor between 1982 and 2010 in that municipality. The means of the leadership score are shown in row 1, the means of the cognitive score in row 2 , and the mean of the earnings score in row 3. Row 4 shows the number of local party-election period observations in each category. Data are drawn from the election years in the 1990s and 2000s (1991, 1994, 1998, 2002, 2006, and 2010). (*) For the enlistment measures of ability, only male politicians in the 1951-1980 cohorts are included, which gives a smaller number of observations for these measures. 


\section{Self-Selection into politics AND PARTy SCREENING}

In the main text of the paper, we have shown that Swedish democracy attracts highly competent individuals even though they clearly have higher opportunity costs from participating in politics. How is this possible? It may be argued that municipal councilors, as part-time politicians, do not face a strong opportunity cost. But we have shown that full-time politicians such as mayors and MPs are also positively selected, despite high pre-office earnings, so the puzzle remains. One explanation is that Swedes are oblivious to pecuniary incentives and opportunity costs - but this seems extreme (and ultimately testable). A less extreme explanation is that material incentives overcome opportunity costs, or that they are aided by intrinsic motivation.

Here, we try to make at least some progress on this puzzle. Three different sets of actors shape the characteristics of the Swedish political class. One is political parties, who have their own objectives and governance structures, which we have discussed in the main text. Another is individuals themselves, who voluntarily give their time to participate in politics. In this section, we analyze the individual incentives to self-select into politics and how self-selection translates into equilibrium (observed) selection under plausible assumptions about party screening. We do not explicitly consider individuals in their role as voters.

\section{CA. Model of self selection}

Main ideas We write down and analyze a simple "Roy model" to shed light on self-selection into politics and on party screening. The model features two periods: individuals decide whether to enter into politics in the first period when "young." The basics of the model track the reality of municipal politics in Sweden: since politics is a part-time occupation, entering politics does not entail leaving one's private occupation when young.

However, those who ascend to higher political ranks (such as mayor or MP) when "old," have to abandon their private occupations, which imposes an opportunity cost. Promotion is probabilistic and the opportunity cost is (for some, only partly) compensated by an attractive wage. Moreover, private occupations become more attractive over time - as compensation when old incorporates a seniority premium, which is occupation-specific (e.g., higher in finance than in elementary-school teaching). While participation in politics when young does not impose an opportunity cost right then, for those who do not obtain the promotion to senior political ranks there is a cost later: due to their split attention while young, those who enter 
politics get lower private seniority premia when old. Individuals differ in terms of their ability - which determines their private occupation payoff - and their intrinsic motivation - modeled as a utility kick from spending time in politics.

Whether an individual who self selects into politics also gets an electable position on the ballot depends on screening by her party. We consider different types of screening, but the results presented in the main text strongly suggest that parties screen positively on competence.

Supply side Consider a set of risk-neutral people, who have to decide whether to supply their services as leisure politicians. Each person is drawn from a continuous distribution jointly defined over two parameters: ability index $Y$ with typical element $y$, and an index of intrinsic motives to serve $P$ with typical element $p$. We assume these parameters are independent, with $P \in[0, \bar{P}>0]$ uniformly distributed and $Y \in[0, \infty)$ distributed according to c.d.f. $G(y)$ with density $g(y)$.

Each person has a two-period horizon and there is no discounting. For simplicity, we assume that going into politics is a once-and-for-all choice in period $1 .^{1}$ Whoever does not go into politics earns $y$ in the first period and expects to earn $\gamma y \geq y$ in the second. In other words, $\gamma \geq 1$ is a measure of the seniority premium (in the data, $\gamma$ is proxied by the earnings-age profile and is allowed to vary across occupations). ${ }^{2}$

Someone who offers to serve gets accepted to run and is elected to the municipal council with probability $q(y)$ - we consider different slopes of the screening function $q(y)$ when discussing the demand side. Elected politicians get intrinsic benefits $\frac{p}{2}$ in each of the two periods. ${ }^{3}$ They must also give up some career: period-1 private earnings are $y$, but period- 2 expected earnings are $(1-\delta) \gamma y$, where $\delta \in[0,1]$ shapes the future opportunity cost of current political involvement. The opportunity cost of politics is thus $\delta \gamma y$, which depends on general ability, private-career prospects, and how these are damaged by a political career.

Some first-period council members are appointed mayors in the second period, in

1. At the cost of additional complexity, the model can be extended to include discounting as well as sequential decisions: a person who entered in period 1 can decide whether to stay or leave in period 2. Discounting adds notational complication only, while sequential decisions create more complex selection patterns which converge to those presented here as the parameter $\delta$ (to be defined shortly) goes to 1 .

2. This model of the supply side is related to those in Delfgaauw and Dur (2007), Francois (2000) and Dal Bó et al. (2013), but among other differences it considers the distinct case of "leisure" politicians who do not give up immediate private sector earnings when entering public service, as well as the role of the seniority premium $\gamma$.

3 . This benefit also captures non-pecuniary, but arguably somewhat extrinsic, returns such as gains in social status. 
which case they earn a political wage $w<\bar{Y}$ plus the intrinsic benefit $\frac{p}{2}$. This happens with probability $\pi$ (in the data, we will allow $w$ and $\pi$ to differ by municipality and party).

Cost-benefit calculation A person decides to become a politician when young whenever

$$
(1+\gamma) y \leq(1-q(y))(1+\gamma) y+q(y)((1+(1-\pi)(1-\delta) \gamma) y+\pi w)+q(y) p
$$

After some algebra, this condition simplifies to

$$
p+\pi(w-(1-\delta) \gamma y) \geq \delta \gamma y
$$

The intrinsic return to politics (the 1st term on the LHS) plus the probability of an income gain when becoming mayor (the 2nd term on the LHS) has to outweigh the opportunity cost of lost career prospects (the RHS).

The entry condition can be re-written as

$$
p \geq p(y) \equiv \pi((1-\delta) \gamma y-w)+\delta \gamma y
$$

Any type $(y, p)$ on the "selection line" $p(y)$ is indifferent between entering politics and staying out. Those above (below) this line want to enter (stay out).

Comparative statics From the selection line defined in (2), we can derive the effect of a change in $w$ as

$$
\frac{d p(y)}{d w}=-\pi<0
$$

meaning that the selection line shifts down and the set of those willing to enter gets larger. As we prove (in the Appendix), independent traits and a uniform distribution over $P$ imply that average ability must go up with any parametric change that shifts the selection line down in parallel fashion.

For parameter $\pi$, we get

$$
\frac{d p(y)}{d \pi}=(1-\delta) \gamma y-w
$$

which in general is ambiguous in sign. Here, the selection line pivots. As ability goes to zero, the derivative approaches $-w$, meaning that the line shifts down. But for very able types, it is positive if $\delta$ is low enough, and the selection line shifts up. 
Then, a higher $\pi$ could conceivably reduce supply of high-ability types. But the data tell a different story, which can only be the case if $\delta$ is high enough that the line shifts down for all types (for any finite $y$, there exists $\delta$ close enough to 1 to render $\frac{d p(y)}{d \pi}$ unambiguously negative).

Finally, for parameter $\gamma$, (2) implies that

$$
\frac{d p(y)}{d \gamma}=(\pi+\delta(1-\pi)) y>0
$$

meaning a steeper age-earnings profile shifts the line up. This discourages entry, lowers average ability, and thus makes for worse supply.

We can summarize the comparative statics in the following (proof in the Appendix):

Proposition 1 Suppose $(p, y)$ are drawn from an independent distribution with $P$ uniformly distributed on $[0, \bar{P}>0]$ and $Y$ distributed on $[0, \infty)$ according to $G(y)$. Then, maximum as well as average competence of people self-selecting into politics increase (weakly) with higher $w$ and lower $\gamma$, and with higher $\pi$ (if $\delta$ is high enough).

Demand side Consider the three types of screening: (i) random selection (e.g., Athenian democracy, with election probability $q$ unrelated to $y$ ); (ii) negative selection (e.g., cronyism, with $q^{\prime}(y)<0$ ); and (iii) positive selection (i.e., meritocracy, with $\left.q^{\prime}(y)>0\right)$.

Since Sweden is a party-based democracy, we assume that a party planner selects from the available candidate pool, anticipating voter demands. The main question is whether our earlier finding that elected politicians have higher ability than the average citizen means that parties screen in a positive way.

The answer is in the affirmative (proof in the Appendix):

Proposition 2 If the party has sufficiently good information on those who supply their services, the fact that elected politicians are more competent than the average citizen implies positive screening by parties. Then, the results in Proposition 1 extend to equilibrium outcomes.

To see this, note first that the term $q(y)$ does not affect the cost-benefit calculus of individuals. Since entry is invariant to party screening, we only need to keep track of the entry condition to characterize the candidate pool. Suppose the planner observes candidate types $(y, p)$ perfectly. We can then show that both random and 
negative screening must lead to politicians less competent than the average citizen, leaving positive screening as the only remaining alternative. ${ }^{4}$

Consider random selection. Given selection line $p=\pi((1-\delta) \gamma y-w)+\delta \gamma y$, the relatively competent self-select out of politics, and expected candidate ability (denote it $\left.E\left(y_{A}\right)\right)$ must be worse than the average ability $E(y)$ in the population. A bit more formally (and abstracting from the fact that $\gamma \geq 1$ ), note that the entry condition implies $p(y) \rightarrow-\pi w$ if $\gamma \rightarrow 0$, such that all citizens enter and $E\left(y_{A}\right) \rightarrow E(y)$. But as shown above, $E\left(y_{A}\right)$ decreases in $\gamma$. This means that when we raise $\gamma$ away from zero, $E\left(y_{A}\right)$ must dip below $E(y)$.

As random screening implies that the average quality of selected politicians is worse than that of the population, the result for negative screening follows immediately.

Because of positive screening, our comparative statics of supply apply to those who are selected into parties and elected. This is easy to see if the party observes types $(p, y)$ perfectly. ${ }^{5}$ Any party that values competence will select individuals with the highest available ability, i.e., those with type $\left(\bar{P}, \frac{\bar{P}+w \pi}{(\pi(1-\delta)+\delta) \gamma}\right)$. Thus, any change in $(\gamma, \pi, w)$ that shifts the line down will (weakly) increase the average and top quality not just among those willing to enter, but also among those elected. Thus, the competence of politicians is weakly increasing in $w$ and $\pi$ (when $\delta$ is high enough), and weakly decreasing in $\gamma$.

Summary Our simple model of supply and its comparative statics resonate with the economic models of selection into politics discussed in the introduction to the main paper, in that they point to clear material motives and opportunity costs as important drivers of self-selection. In addition, our model highlights intrinsic motives, dynamic career concerns, and helps think about how, given self-selection, screening would affect final selection.

\section{CB. Evidence on Self-selection}

In this subsection, we check whether the patterns in the data are consistent with the predictions of our model.

4. While our conclusion of positive screening relies on the assumptions of our model, specifically the one on the distribution of traits, it is corroborated by evidence presented in the paper on the screening role of parties.

5 . The argument can be extended to the case when the party observes types imperfectly at the cost of some additional notation and algebra. 
Mayor earnings One prediction is that higher monetary remuneration $(w$ in the model) attracts more competent politicians. To explore this, we look at the salary of mayors, the only (or one of few) full-time paid position(s). ${ }^{6}$ Mayor salaries vary substantially across municipalities. In 2011, their average annual earnings was 632,400 SEK (about 79,044 USD), with a standard deviation of 213,000 SEK.

To relate the value of this wage to income opportunities in the municipality, we normalize the mayor's annual earnings by average earnings among all inhabitants above 18 years of age. This approximates the material payoff to the position of mayor.

We consider a sample of all local parties that ever appointed a mayor in the period 1991-2010. Because the probability of becoming mayor varies by rank on the municipal party list - first-ranked politicians being (overwhelmingly) the most likely, second-ranked being next in line, and so on - we select the top-five people from every electoral ballot and create five samples, one for each list rank.

Then, we use OLS to estimate

$$
Q_{i, r, m, t}=\alpha_{t}+\beta_{r} w_{m, t}+\varepsilon_{i, r, t}
$$

where $Q_{i, r, m, t}$ is one of our three ability measures for politician $i$ with list rank $r$, in municipality $m$ in election period $t, \alpha_{t}$ is an election-period fixed effect, and $w_{m, t}$ is the (normalized) mayoral wage in municipality $m$ and election period $t$. The coefficient of interest is $\beta_{r}$, the linear relation between the mayor's relative wage and the selection of politicians for rank $r$. If a higher salary attracts higher-ability individuals, $\beta_{r}$ should be positive. Moreover, if high earnings attract high-ability candidates to seek positions with a higher probability to become mayor, $\beta_{r}$ should be the highest for $r=1$.

The estimates for the cognitive and leadership scores show a positive and significant relationship between mayoral wage and selection into the top rank of the list (from which mayors are almost exclusively appointed). A $1 \sigma$ increase in relative mayoral wages is associated with a higher leadership score of individuals in the top rank (averaging out across parties) by $0.28 \sigma$, and a higher cognitive score by $0.19 \sigma$.When restricting attention to leadership and cognitive scores, we do not see evidence of positive effects for the remaining ranks. The estimates for earnings score are positive and significant for ranks 1,2, and 4. The largest point estimate is for the top rank, which shows that a $1 \sigma$ higher relative mayoral wages is associated with

6. We could also add the prospects of a promotion to a position in the national parliament. Because the probability of this event is so low (on the order of $0.5 \%$ ), this would not change any of the results to be shown here. 
an higher earnings score by $0.19 \sigma$. Figure A.5 in this Online Appendix plots our estimate of interest from equation (3), from our five $r$-samples. These correlations lend some support to the idea from the model that stronger pecuniary prospects in politics, in the form of a higher mayor's wage, tend to draw more able candidates.

Age-earnings profiles Another prediction from our simple model is that selection is less positive for people with a higher seniority premium ( $\gamma$ in the model). We capture this premium by computing occupation-specific age-earnings profiles, in two ways. One builds on a categorization of easily identifiable education types, which cover roughly 70 percent of the working-age population. The other way builds on sectors of employment, the same sectors that go into the estimation of the Mincer equation in (1) in Section 3 of the main text and underlying our measure of earnings score. As in that estimation, we divide people in each sector into two groups, one with tertiary education and one without. This categorization covers the whole workingage population, but does not lend itself to as easy labeling as the first method.

For each labor-market segment and each classification, we first compute the average rate of (nominal) earnings growth over the course of the sample. Then, we compute separate selection indices, like that in section VI.A. in the main text, for our three ability measures in each occupation. Finally, we regress these selection indices on the age-earnings profile in each occupation. Thus, we run six regressions (three ability measures $x$ two types of occupation classification). We find that in five of the six regressions individuals are significantly less positively selected when they belong to occupational categories with more rapidly rising earnings. In fact, a few occupations with very rapidly increasing earnings display negative selection.

Figure A.6 in this Online Appendix graphs the data in each regression, where each row of plots shows a specific ability selection index - from top to bottom, the leadership score, the cognitive score, and earnings score. The columns apply to an occupation division: educational categories to the left and employment sectors to the right. Overall, this exercise yields substantial support to one of the less direct predictions of the model.

Appointment probabilities The remaining prediction concerns the effect of prospects for political promotion ( $\pi$ in the model). The probability of landing a paid political position like the mayorship varies markedly with the political status of the party. Some parties are in a strong majority position, making their appointing the mayor highly probable. Other parties are small in size and/or belong to the opposition bloc, making their appointing the mayor highly unlikely. We thus classify parties into categories depending on the opportunity they afford in terms of political career 
in each municipality.

To do that, for each party and municipality, we simply calculate the proportion of election periods between 1982 and 2010 that the party appointed the mayor. Specifically, to proxy for parameter $\pi$, we divide parties into four groups: (1) 0 percent probability, (2) 1-50 percent probability, (3) 51-99 percent probability, and (4) 100 percent probability.

We compare competence selection indices across these four categories. We want to know: (i) Does type (4), with the highest probability of appointing the mayor, stand out in terms of positive selection? and (ii) Do parties of other types, especially type (1), still show positive selection of politicians?

Table B.4 in this Online Appendix shows selection indices for each of the groups (1)-(4). We find that parties that are sure to appoint the mayor indeed have a better selection of their top-ranked politicians. ${ }^{7}$ Hence, the political career prospects do seem to matter for positive selection, as our model suggests. This result is in sync with the result on mayoral wages.

In addition, we find no evidence of adverse (or even neutral) selection for the rank and file in parties with a small or zero probability of promotion. The average representative is as qualified in the party category with the weakest career prospects as in the party categories with better prospects. In terms of our model, this suggests that material motives tell only part of the self-selection story and that intrinsic motives must also play an important role (in our model, individuals with $p=0$ would not enter politics if they stood no chance to obtain a prized mayoral position).

Bottom line Our simple model establishes that if screening is either neutral or positive (a "well behaved" demand side), the predictions of our self-selection model (the supply side of politics) will translate into patterns of selection observed in equilibrium. The findings in the main text do support the notion that screening is positive. In addition, the predictions on self-selection derived here are also broadly consistent with the data. Our findings suggest that both material and intrinsic motives matter in political entry. Material motives appear to matter in terms of direct compensation, as this is relevant to outweigh opportunity costs in an intuitive way. Moreover, less intuitive effects highlighted by the model are also consistent with the data, such as those stemming from a dynamic opportunity cost created by different age-wage profiles across occupations.

7. Majority parties have larger party delegations on average, which means that the average competence among the rank and file is pulled down by moving further down the competence distribution. 


\section{Appendix - proofs}

Proof of Proposition 1 The set of willing politicians, the "applicant pool", is $(y, p) \mid p \geq(\pi(1-\delta)+\delta) \gamma y-\pi w$ or $y \leq \frac{p+\pi w}{(\pi(1-\delta)+\delta) \gamma}$.

The measure of the applicant pool is,

$$
\int_{0}^{\bar{P}} \int_{0}^{\frac{p+\pi w}{(\pi(1-\delta)+\delta) \gamma}} g(y) d y \frac{1}{\bar{P}} d p
$$

and the average quality in the applicant pool (denoted by $\left.E\left(y_{A}\right)\right)$ is,

$$
E\left(y_{A}\right)=\frac{\int_{0}^{\bar{P}} \int_{0}^{\frac{p+\pi w}{(\pi(1-\delta)+\delta) \gamma}} y g(y) d y \frac{1}{\bar{P}} d p}{\int_{0}^{\bar{P}} \int_{0}^{\frac{p+\pi w}{(\pi(1-\delta)+\delta) \gamma}} g(y) d y \frac{1}{\bar{P}} d p} .
$$

Denote $\varphi \equiv \frac{p+\pi w}{(\pi(1-\delta)+\delta) \gamma} \equiv \frac{p+a}{\psi}$, with $a \equiv \pi w$ and $\psi \equiv(\pi(1-\delta)+\delta) \gamma$.

Maximum competence The most competent type willing to enter politics is $\left(\bar{P}, \bar{y} \equiv \frac{\bar{P}+\pi w}{(\pi(1-\delta)+\delta) \gamma}\right)$. Note that $\frac{d \bar{y}}{d w}=\frac{\pi}{(\pi(1-\delta)+\delta) \gamma}>0, \frac{d \bar{y}}{d \gamma}=-\frac{(\bar{P}+\pi w)}{(\pi(1-\delta)+\delta) \gamma^{2}}<0$ showing that the maximum competence increases with $w$ and decreases with $\gamma$. Now observe that if $\delta=1, \frac{d \bar{y}}{d \pi}=\frac{w}{\gamma}>0$ and the statement in the proposition follows from continuity.

Average competence We now prove the statements on average competence.

Effects of $w$ and $\gamma$. Since $\varphi$ is increasing in $w$ and decreasing in $\gamma$, establishing $\frac{d E\left(y_{A}\right)}{d \varphi}>0$ will prove $\frac{d E\left(y_{A}\right)}{d w}>0$ and $\frac{d E\left(y_{A}\right)}{d \gamma}<0$. Write out the expression for $\frac{d E\left(y_{A}\right)}{d \varphi}$ as

$$
\begin{aligned}
\frac{d E\left(y_{A}\right)}{d \varphi} & =\frac{\int_{0}^{\bar{P}} \varphi g(\varphi) \frac{1}{\bar{P}} d p}{\int_{0}^{\bar{P}} G(\varphi) \frac{1}{\bar{P}} d p}-\frac{\int_{0}^{\bar{P}} \int_{0}^{\varphi} y g(y) d y \frac{1}{\bar{P}} d p}{\left(\int_{0}^{\bar{P}} G(\varphi) \frac{1}{\bar{P}} d p\right)^{2}} \int_{0}^{\bar{P}} g(\varphi) \frac{1}{\bar{P}} d p \\
& =\frac{\int_{0}^{\bar{P}} g(\varphi) \frac{1}{\bar{P}} d p}{\int_{0}^{\bar{P}} G(\varphi) \frac{1}{\bar{P}} d p} \cdot\left(\frac{\int_{0}^{\bar{P}} \varphi g(\varphi) \frac{1}{\bar{P}} d p}{\int_{0}^{\bar{P}} g(\varphi) \frac{1}{\bar{P}} d p}-\frac{\int_{0}^{\bar{P}} \int_{0}^{\varphi} y g(y) d y \frac{1}{\bar{P}} d p}{\int_{0}^{\bar{P}} G(\varphi) \frac{1}{\bar{P}} d p}\right)
\end{aligned}
$$


and use the equality $\varphi=\frac{p+a}{\psi}$, to get

$$
\begin{aligned}
& =\frac{\int_{0}^{\bar{P}} g(\varphi) d p}{\int_{0}^{\bar{P}} G(\varphi) d p} \cdot\left(\frac{\int_{\frac{a}{\psi}}^{\frac{\bar{P}+a}{\psi}} y g(y) d y}{\int_{\frac{a}{\psi}}^{\frac{\bar{P}+a}{\psi}} g(y) d y}-\left(\frac{\int_{0}^{\bar{P}} \int_{0}^{\frac{a}{\psi}} y g(y) \frac{1}{\bar{P}} d y d p+\int_{0}^{\bar{P}} \int_{\frac{a}{\psi}}^{\frac{a+p}{\psi}} y g(y) d y \frac{1}{\bar{P}} d p}{\int_{0}^{\bar{P}} \int_{0}^{\frac{a}{\psi}} g(y) d y \frac{1}{\bar{P}} d p+\int_{0}^{\bar{P}} \int_{\frac{a}{\psi}}^{\frac{a+p}{\psi}} g(y) d y \frac{1}{\bar{P}} d p}\right)\right) \\
& =\frac{\int_{0}^{\bar{P}} g(\varphi) d p}{\int_{0}^{\bar{P}} G(\varphi) d p} \cdot\left(\frac{\int_{\frac{a}{\psi}}^{\frac{\bar{P}+a}{\psi}} y g(y) d y}{\int_{\frac{a}{\psi}}^{\frac{\bar{P}+a}{\psi}} g(y) d y}-\left(\begin{array}{c}
\frac{\int_{0}^{\bar{P}} \int_{0}^{\frac{a}{\psi}} y g(y) \frac{1}{P} d y d p}{\int_{0}^{\bar{P}} \int_{0}^{\frac{a}{\psi}} g(y) d y \frac{1}{P} d p+\int_{0}^{\bar{P}} \int_{\frac{a}{\psi}}^{\frac{a+p}{\psi}} g(y) d y \frac{1}{P} d p} \\
\frac{\int_{0}^{\bar{P}} \int_{\frac{a}{\psi}}^{\frac{a+p}{\psi}} y g(y) d y \frac{1}{P} d p}{\int_{0}^{\bar{P}} \int_{0}^{\frac{a}{\psi}} g(y) d y \frac{1}{P} d p+\int_{0}^{\bar{P}} \int_{\frac{a}{\psi}}^{\frac{a+p}{\psi}} g(y) d y \frac{1}{P} d p}
\end{array}\right)\right) .
\end{aligned}
$$

Changing the order of integration, so that $\int_{0}^{\bar{P}} \int_{\frac{a}{\psi}}^{\frac{a+p}{\psi}} y g(y) d y \frac{1}{\bar{P}} d p=\int_{\frac{a}{\psi}}^{\frac{a+\bar{P}}{\psi}} \int_{\psi y-a}^{\bar{P}} y g(y) d p d y \frac{1}{\bar{P}}=$ $\int_{\frac{a}{\psi}}^{\frac{a+\bar{P}}{\psi}} \frac{\bar{P}-(\psi y-a)}{\bar{P}} y g(y) d y$ and $\int_{0}^{\bar{P}} \int_{\frac{a}{\psi}}^{\frac{a+p}{\psi}} g(y) d y \frac{1}{\bar{P}} d p=\int_{\frac{a}{\psi}}^{\frac{a+\bar{P}}{\psi}} \frac{\bar{P}-(\psi y-a)}{\bar{P}} g(y) d y$, we can write

$$
=\frac{\int_{0}^{\bar{P}} g(\varphi) d p}{\int_{0}^{\bar{P}} G(\varphi) d p} \cdot\left(\frac{\int_{\frac{a}{\psi}}^{\frac{\bar{P}+a}{\psi}} y g(y) d y}{\int_{\frac{a}{\psi}}^{\frac{\bar{P}+a}{\psi}} g(y) d y}-\left(\begin{array}{c}
\frac{\int_{0}^{\frac{a}{\psi}} y g(y) d y}{\int_{0}^{\frac{a}{\psi}} y g(y) d y+\int_{\frac{a}{\psi}}^{\frac{a+P}{\psi}} \frac{\bar{P}-(\psi y-a)}{P} g(y) d y} \\
\frac{\int_{\frac{a}{\psi}}^{\frac{a+\bar{P}}{\psi}} \frac{\bar{P}-(\psi y-a)}{P} y g(y) d y}{\int_{0}^{\frac{a}{\psi}} y g(y) d y+\int_{\frac{a}{\psi}}^{\frac{a+\bar{P}}{\psi}} \frac{\bar{P}-(\psi y-a)}{P} g(y) d y}
\end{array}\right)\right.
$$

or

$$
=\frac{\int_{0}^{\bar{P}} g(\varphi) d p}{\int_{0}^{\bar{P}} G(\varphi) d p} \cdot\left(\frac{\int_{\frac{a}{\psi}}^{\frac{\bar{P}+a}{\psi}} y g(y) d y}{\int_{\frac{a}{\psi}}^{\frac{\bar{P}+a}{\psi}} g(y) d y}-\left(\begin{array}{c}
\frac{\int_{0}^{\frac{a}{\psi}} g(y) d y}{\int_{0}^{\frac{a}{\psi}} g(y) d y+\int_{\frac{a}{\psi}}^{\frac{a+P}{\psi}} \frac{(\bar{P}-(\psi y-a))}{P} g(y) d y} \cdot \frac{\int_{0}^{\frac{a}{\psi}} y g(y) d y}{\int_{0}^{\frac{a}{\psi}} g(y) d y}+ \\
\frac{\int_{\frac{a}{\psi}}^{\frac{a+\bar{P}}{\psi}} \frac{(\bar{P}-(\psi y-a))}{P} g(y) d y}{\int_{0}^{\frac{a}{\psi}} g(y) d y+\int_{\frac{a}{\psi}}^{\frac{a+P}{\psi}} \frac{(\bar{P}-(\psi y-a))}{P} g(y) d y} \cdot \frac{\int_{\frac{a}{\psi}}^{\frac{a+\bar{P}}{\psi}} \frac{(\bar{P}-(\psi y-a))}{P} y g(y) d y}{\int_{\frac{a}{\psi}}^{\frac{a+P}{\psi}} \frac{(\bar{P}-(\psi y-a))}{P} g(y) d y}
\end{array}\right),\right.
$$


which can be simplified as

$$
=\frac{\int_{0}^{\bar{P}} g(\varphi) d p}{\int_{0}^{\bar{P}} G(\varphi) d p} \cdot(\underbrace{\frac{\int_{\frac{a}{\psi}}^{\frac{\bar{P}+a}{\psi}} y g(y) d y}{\int_{\frac{a}{\psi}}^{\frac{\bar{P}+a}{\psi}} g(y) d y}}_{A_{1}}-(\alpha_{1} \cdot \underbrace{\frac{\int_{0}^{\frac{a}{\psi}} y g(y) d y}{\int_{0}^{\frac{a}{\psi}} g(y) d y}}_{A_{2}}+\alpha_{2} \cdot \underbrace{\frac{\int_{\frac{a}{\psi}}^{\frac{a+\bar{P}}{\psi}} y \frac{(\bar{P}-(\psi y-a))}{\bar{P}} g(y) d y}{\int_{\frac{a}{\psi}}^{\frac{a+\bar{P}}{\psi}} \frac{(\bar{P}-(\psi y-a))}{\bar{P}} g(y) d y}}_{A_{3}})),
$$

where

$$
\begin{aligned}
& \alpha_{1}=\frac{\int_{0}^{\frac{a}{\psi}} g(y) d y}{\int_{0}^{\frac{a}{\psi}} g(y) d y+\int_{\frac{a}{\psi}}^{\frac{a+\bar{P}}{\psi}} \frac{(\bar{P}-(\psi y-a))}{\bar{P}} g(y) d y} \\
& \alpha_{2}=\frac{\int_{\frac{a}{\psi}}^{\frac{a+\bar{P}}{\psi}} \frac{(\bar{P}-(\psi y-a))}{\bar{P}} g(y) d y}{\int_{0}^{\frac{a}{\psi}} g(y) d y+\int_{\frac{a}{\psi}}^{\frac{a+\bar{P}}{\psi}} \frac{(\bar{P}-(\psi y-a))}{\bar{P}} g(y) d y} .
\end{aligned}
$$

Note that $1 \geq \alpha_{i} \geq 0, i=1,2$ and $\alpha_{1}+\alpha_{2}=1$. Then, if $\int_{\frac{a}{\psi}}^{\frac{\bar{P}+a}{\psi}} y g(y) d y>0$ (i.e. the support of $Y$ covers a neighborhood of some point on the selection line), $A_{1}>A_{2}$ and $A_{1}>A_{3}$ since $\frac{\bar{P}-(\psi y-a)}{\bar{P}}$ is a decreasing function in $y$. It follows that $\frac{d E\left(y_{A}\right)}{d \varphi}>0$.

Effects of $\pi$. The effect of $\pi$ on $\varphi$ is ambiguous and hence so is the effect of $\pi$ on $E\left(y_{A}\right)$. This effect becomes unambiguous only as $\delta \rightarrow 1$ and $y$ finite. At $\delta=1$, $\varphi=\frac{p+\pi w}{\gamma}$, and the effect of $\pi$ is similar to that of $w$, and $\frac{d E\left(y_{A}\right)}{d \pi}>0$.

Proof of Proposition 2 Suppose the party observes types $(y, p)$ perfectly.

Negative screening. Here, the party selects an ability type of zero, which yields more incompetent politicians than the average citizen.

Random (Athenian) screening. This obviously does not require the party to observe types, as it can make random offers to those who volunteer. Clearly, the party obtains politicians with the average competence in the volunteer pool (denoted $\left.E\left(y_{A}\right)\right)$. To show that this is worse than average competence in the population, we use the identity $\varphi \equiv \frac{p+\pi w}{(\pi(1-\delta)+\delta) \gamma}$, noting that $E\left(y_{A}\right)<E(y)$ requires

$$
E\left(y_{A}\right) \equiv \frac{\int_{0}^{\bar{P}} \int_{0}^{\varphi} y g(y) d y \frac{1}{\bar{P}} d p}{\int_{0}^{\bar{P}} \int_{0}^{\varphi} g(y) d y \frac{1}{\bar{P}} d p}<\frac{\int_{0}^{\bar{P}} \int_{0}^{\infty} y g(y) d y \frac{1}{\bar{P}} d p}{\int_{0}^{\bar{P}} \int_{0}^{\infty} g(y) d y \frac{1}{\bar{P}} d p} \equiv E(y)
$$


This inequality follows from the fact that $\varphi<\infty$ and $E\left(y_{A}\right)$ is increasing in $\varphi$.

Positive screening. This is the only form of screening that can deliver politicians who, on average, are more able than the average citizen. By continuity, very mildly positive screening - arbitrarily close to random screening - will yield politicians worse than the population on average. Therefore, positive screening must be pronounced enough for politicians to be better than the average. Under the assumptions that types are perfectly observable and both traits are valuable, the party will select types $\left(\bar{P}, \frac{\bar{P}+w \pi}{(\pi(1-\delta)+\delta) \gamma}\right)$. 


\section{REFERENCES}

Dal Bó, Ernesto, Frederico Finan, and Martín Rossi. Strengthening State Capabilities: The Role of Financial Incentives in the Call to Public Service. The Quarterly Journal of Economics, 128(3):1169-1218, 2013. URL http://EconPapers.repec .org/RePEc : oup:qjecon:v:128:y:2013:i:3:p:1169-1218.

Delfgaauw, Josse and Robert Dur. Signaling And Screening of Workers' Motivation. Journal of Economic Behavior \& Organization, 62(4):605-624, 2007.

Francois, Patrick. 'Public Service Motivation' as an Argument for Government Provision. Journal of Public Economics, 78(3):275-299, 2000.

Nilsson, Peter J. Alcohol Availability, Prenatal Conditions, and Long-term Economic Outcomes. Journal of Political Economy, forthcoming, 2014. 